Article

\title{
Predicting Entrepreneurial Intentions and Pre-Start-Up Behaviour among Asnaf Millennials
}

\author{
Tengku Mohd Azizuddin Tuan Mahmood ${ }^{1}$, Abdullah Al Mamun ${ }^{1, *}$, Ghazali Bin Ahmad ${ }^{2}$ and \\ Mohamed Dahlan Ibrahim ${ }^{1}$ \\ 1 Faculty of Entrepreneurship and Business, Universiti Malaysia Kelantan, City Campus, Pengkalan Chepa, \\ 16100 Kota Bharu, Kelantan, Malaysia \\ 2 Faculty of Hospitality, Tourism and Wellness, Universiti Malaysia Kelantan, City Campus, Pengkalan Chepa, \\ 16100 Kota Bharu, Kelantan, Malaysia \\ * Correspondence: abdullah.a@umk.edu.my or mamun7793@gmail.com; Tel.: +60-0133003630
}

Received: 15 August 2019; Accepted: 4 September 2019; Published: 10 September 2019

\begin{abstract}
The study referred to the theory of planned behaviour in determining how the selected factors (innovativeness, proactive personality, need of achievement, internal locus of control, risk-taking propensity, lifestyle integration, social networking, resource and opportunity recognition, attitude towards entrepreneurship, subjective norms, and perceived behavioural control) influenced the entrepreneurial intentions and pre-start-up behaviour among the Asnaf millennials in Malaysia. This study collected cross-sectional survey data, which are quantitative data from 310 randomly selected Asnaf millennials from Kelantan, Malaysia using structured interviews. This study used Partial Least Squares Structural Equation Modeling PLS-SEM to analyse the data. The result confirmed the indirect influence (entrepreneurial intention) of attitude towards entrepreneurship, subjective norms, and perceived behavioural control on the pre-start-up behaviour. Findings revealed that all antecedents have a positive and statistically significant effect on attitude towards entrepreneurship, subjective norms, and perceived behavioural control, with an exception to risk-taking propensity. Hence, it is suggested that development programs and policies should enhance the innovativeness and opportunity recognition competency, provide access to working capital, and build a platform to promote entrepreneurial networking in increasing entrepreneurial intention among the low-income Asnaf millennials in Malaysia.
\end{abstract}

Keywords: entrepreneurial Intention; pre-start-up behaviour; theory of planned behaviour; Asnaf millennial

\section{Introduction}

The underlying pre-start-up phase that responds to new venture engagement is a critical issue nowadays. Since the early 1980s, a considerable body of literature has addressed new venture creation, which required a series of actions [1]. The entrepreneurial process relies on the series of transitions on conceiving and perceiving a start-up as a personal option depending on multiple reasons, including job loss or threat of income loss [2]. This situation motivates them to seek entrepreneurship as a medium of income generation, which drives them to visualise an idea or opportunity while exploring the option of starting a business. New venture creation is an adventure process that determines the challenge with high risks and uncertainties. Many start-up founders overlooked some points or critical stages in committing new venture creation as a personal option, and this issue could increase the rate of failure among new entrepreneurs [3]. People with positive intention towards entrepreneurship focus on pre-start-up activities before new venture creation [4].

Government and development organisations are encouraging the young generation to engage in entrepreneurial activities instead of focusing on jobs $[5,6]$. The local government and developing 
organisations in Malaysia predominantly focus on ways to promote entrepreneurial activities among the young generation from low-income households, such as millennials from the Asnaf community. It is believed that technical and vocational enterprise development training can promote entrepreneurial activities among Asnaf millennials (referred to as millennials from low income households receiving a monthly donation from Majlis Agama Islam Kelantan, who are born between 1980 and 2000) in improving their socio-economic conditions. Therefore, it is important to improve our knowledge and understanding regarding the determinants and processes that focus on entrepreneurial start-up activities among Asnaf millennials. This strategy is expected to lead to better policies and programs in promoting entrepreneurial activities among low-income households for sustainable socio-economic development in Malaysia.

The existing theories and models, and the evidence is fragmented in explaining the new venture establishment [7]. Besides that, there is a lack of common understanding regarding the concept of the pre-start-up phase, and scholars focus on different aspects of the phenomenon. A study by DeTienne [3] highlighted that an individual has high potential to exist in entrepreneurial activity and identified three major themes, namely alternative, calculative, and normative forces, which characterize research about entrepreneurs and new venture establishment in the initial phase. The research highlighted the importance of studying the existing studies on the effort and taking steps forward to define the themes.

The most common human behaviour model has been extensively used to forecast intention behaviour (i.e., theory of planned behaviour (TPB), theory of reasoned action), and many facets of the relationship in each belief were identified in the present study. It was found that there were many suggestions from previous studies that applied the theory of decomposed theory of planned behaviour (DTPB) in various study settings. In the entrepreneurship setting, the DTPB model emphasises on identifying belief structures and antecedents of intention [8]. It is easier to analyse and predict various determinants of behavioural beliefs using the DTPB. Earlier studies adopted the TPB and DTPB in various settings to examine the effect of various factors on entrepreneurial intention across the world. A study by Asimakopoulos, Hernández, and Miguel [9] found a positive effect of entrepreneurial education and self-efficacy on entrepreneurial intention among engineering students in Spain. Another recent study among Spanish youth reported that youth with a family business and high perceptions about health and quality of life possess a relatively higher level of entrepreneurial intention than that of others [10]. A study by Wach and Wojciechowski [11] reported that attitude, subjective norms, and perceived behavioural control determine the entrepreneurial intentions of students in Poland. Among Chinese engineering students, Fang and Chen [12] suggested that a subjective approach to entrepreneurship education can enrich entrepreneurial intentions. In Romania, a study conducted by Voda and Florea [13] reported that the locus of control, need for achievement, and entrepreneurial education are the key determinants for entrepreneurial intention among university students. A study by Paunescu, Popescu, and Duennweber [14] reported that the feasibility, social stability, income, education, and working status affect entrepreneurial intention among Romanians. The present study applied the DTPB to understand the complex relationship between the belief structures and how they affect millennials' entrepreneurial intention on pre-start-up activities. The DTPB has become one of the most utilised theories in explaining and predicting behaviours of individuals by decomposing a smaller construct in each belief (attitudinal, norm, control). Besides that, the DTPB is used to explain and predict intentions and behaviours in various research fields, such as consumer behaviour [15], web usage [16], usage intention [17], user intention [18], mobile application [19], M-commerce [20], utilitarian green products and hedonic green products [21], behavioural intention towards electric vehicles [22,23], behavioural intention towards certified aquaculture products [24], and green consumption [25].

Therefore, this study focused on exploring the process of new venture establishment among Asnaf millennials by examining the trend of new venture establishment theories. This study examined Asnaf millennials' effort in new venture establishment and identified factors that may affect entrepreneurial intention (ENTI) and pre-start-up behaviour (PRSB). Specifically, this study examined how innovativeness, proactive personality, the need for achievement, internal locus of control, 
risk-taking propensity, lifestyle integration, social networking, resource and opportunity recognition, attitude towards entrepreneurship, subjective norms, and perceived behavioural control influenced the entrepreneurial intentions and pre-start-up behaviour among Asnaf millennials in Malaysia.

\subsection{Study Context: Entrepreneurship}

Entrepreneurship is the backbone of a country's development. Entrepreneurship plays a pivotal role in driving economic growth and reducing poverty, especially in rural areas [26]. Entrepreneurship has the potential for economic growth. There are several policies and programs that inspired more low-income Malaysians to participate in this sector. The Malaysian government focuses on entrepreneurship as a mean of generating incomes for low-income households. It is believed that the programs can improve the productivity of entrepreneurs, which can produce higher incomes.

\subsubsection{Millennials and Entrepreneurship}

Millennials are born between 1980 and 2000 [27]. Millennials search for new opportunities for self-development. Millennials have personality traits [27] that are closely related to entrepreneurs, such as the way people behave, which is essential for business continuity [28]. The relationship between millennials and entrepreneurship is nuanced and complex. Previous study suggested that the young generation should be researched and analysed for entrepreneurial development [29]. This is supported by Rahman and Ahmad [5], who stated that the members of the young generation are more likely to succeed in business because they are highly exposed to the risk of failure and focus on issues, diverse solutions, networking, and break down barriers [30]. Entrepreneurship is linked to self-employment, which is a solution for employability among youths [31]. A study conducted by Barton, Schaefer, and Canavati [32] found that social and personal achievement and professional independence are key motivating factors that influence students' intentions towards social entrepreneurship.

\subsubsection{Pre-Start-Up Phases}

New venture creation can be defined as a process of entrepreneurship. The early stage, such as potential pitfalls or creating decisions, may infuse the entrepreneurship process that can lead to new venture ideas, as well as shaping ENTI, the preparation stage, and networking in the initial phase [33]. The process of venture creation is synonymous with pre-start-up [34]. The pre-start-up phase is the series of transitions by a person who perceives a start-up as a personal option [34]. Although the definitions may vary, an entrepreneur who is involved in pre-start-up can be defined as a person who introduces serious actions to kick start a practical business [35,36]. The pre-start-up is the effort of an individual's activities for a specific action to make the entrepreneurship possible [37]. Thus, it is important to examine the new venture development process and the growth of entrepreneurship in the early stage. Early-stage entrepreneurship research should recognise the factors that influence the pre-start-up development [38].

Identification of the pre-start-up phase is important for new venture creation [33]. The enhancement of knowledge on the pre-start-up through an understanding of the early phases serves as a basis for start-up decisions and commitment [34]. According to this view, early stages are designed and established based on the number of actions that are directly led by the person who is inclined to venture formation. Thus, a greater understanding of individual entrepreneurs will provide valuable insight into the pre-start-up phase.

\subsubsection{Pre-Start-Up Behaviour (PRSB)}

Pre-launch or pre-start-up is the preparations that include market research, budgeting, as well as preparation of marketing and business plans [39]. Pre-start-up is the effort of an individual in taking a specific action that makes entrepreneurship possible [37]. In the new venture creation phase, pre-start-up can provide value-added activities and processes to kick start a venture as a personal choice [34]. PRSB serves as the behavioural expectancies in providing better predictions of behaviour 
in new venture creation [37,40]. An individual who has a serious business idea can respond highly to positive evaluation in generating many real businesses. The study recognised the function of pre-start-up activities in encouraging growth momentum and a foundation for future profits [37]. The more time and efforts of activities put into accomplishing a task means the entrepreneur is one step closer to creating a new venture [41].

\subsection{Study Context: Asnaf Millennials}

Asnaf millennials refer to the children of the needy and poor who were born between 1998 and 2000. It is believed that the childbearing stage and unemployment are situations when families are more likely to be poor. The impact of poverty is higher during adolescence as children need more monetary support during this stage. From the Asnaf millennials' perspective, they are more likely to be poor as they are not privileged to have the affluence that is enjoyed by the general society. Government agencies, such as Islamic Religious Council States, have initiated several programmes, including educational support and on-going assistance, to change the lives and improve the socio-economic conditions of low-income households in Malaysia.

\section{Literature Review}

\subsection{Decomposed Theory of Planned Behaviour}

Taylor and Todd [8] introduced decomposed theory of planned behaviour in which attitudinal, normative, and control beliefs are categorised into multi-dimensional constructs. The decomposed construct helps in understanding the complex relationship in various study settings by testing the complete model with actual behaviour measures. This study integrated the psychological factors that influenced attitude towards entrepreneurship (ATE), followed by subjective norms (SUNs) and perceived behavioural control (PBC), which are decomposed into a smaller construct. This action enabled the DTPB to explain the link between the variables. This study used DTPB to understand all the antecedents of ATE, SUN, and PBC, as well as how they affected ENTI and PRSB.

\subsection{ATE and Entrepreneurial Intention}

Attitude refers to the level of a person's favourable or unfavourable assessment of performing a behaviour [42]. ATE is a personal desirability in becoming an entrepreneur, which precedes ENTI [43-45] and forming a person's intention towards behaving in certain manners [43]. There is a positive relationship between ATE and ENTI $[46,47]$ in which people who have positive ATE are more likely to be self-employed [48]. The following is the hypothesised prediction:

Hypothesis $\mathbf{1}\left(\mathbf{H}_{\mathbf{1}}\right)$. ATE has a positive effect on ENTI for Asnaf millennials.

Personality Traits and ATE

Personality traits refer to non-cognitive skills, which inherently describe the unique character of a person [49,50], such as thoughts, emotions, feelings, and behaviours, on the tendency to act in particular ways and circumstances. Personality refers to enduring traits and attitudes, which are transient, and traits can direct the attitudes towards situations or people by demonstrating a person's will to work, organise, interact with others, and the level of creativity [51]. A study conducted by Rokhman and Ahamed [52] highlighted that social factors (i.e., family background, education system, and social status) and psychological factors (i.e., need for achievement, propensity to risk, and locus of control) are the key indicators influencing entrepreneurial intention among Indonesian students. Based on earlier studies on entrepreneurial traits, this study selected five personality traits, including innovativeness, proactive personality, need for achievement, internal locus of control, and risk-taking propensity, in examining their effects on ATE. The five traits are important for the creation of a new venture [1]. 
The common background factor associated with entrepreneurship has led to business survival in the entrepreneurship process and has received attention in the entrepreneurial literature [53].

Innovativeness (IN) refers to a person's ability and tendency to have creative thinking, innovate new and useful ideas, form new markets, as well as initiating new products and services [54,55]. An individual who possesses novel solutions and creative thinking for entrepreneurship needs to think innovatively in improving their performance [56]. In the business setting, innovative leaders have creative thinking and present new and useful ideas, form new markets, and initiate new products and services [54,57]. Prior studies revealed the IN trait on ATE as a predictor [58] that provides multiple significant effects [59]. Therefore, this study hypothesised the following:

Hypothesis $\left(\mathbf{H}_{1 \mathbf{a}}\right)$. IN has a positive effect on ATE among the Asnaf millennials in Malaysia.

Proactive personality (PP) is unrestricted by situational forces that can cause environmental change. $\mathrm{PP}$ is a specific type of personality trait [60]. A proactive person would search for chances and initiatives, as well as persevere in his or her action to accomplish change. The person can adjust and tolerate situations [60]. Proactiveness is a trait of influencing and leading the future instead of waiting for others to influence the person as the individual searches for chances and admits failure [61]; being able to anticipate future problems, needs for change, and improvement [55]. The person can seize environmental opportunities [62] and predict a wide range of behaviours [60]. This study therefore hypothesised the following:

Hypothesis $\left(\mathbf{H}_{\mathbf{1 b}}\right)$. PP has a positive effect on ATE among the Asnaf millennials in Malaysia.

Need for achievement (NA) refers to the tendency of a person who is motivated to set challenging goals and excel in tasks [63]. A person with a high NA would plan in advance for job performance regardless of the tasks [64] due to the satisfaction of personal achievement without disappointment [65] in maintaining high standards to complete difficult tasks [66]. Numerous studies found that NA could predict ATE [58], as people with high NA are more likely to be entrepreneurs [53]. This study therefore hypothesised the following:

Hypothesis $\left(\mathbf{H}_{\mathbf{1 c}}\right)$. NA has a positive effect on ATE among the Asnaf millennials in Malaysia.

Internal locus of control (IC) is viewed as a personal control that determines outcomes [67]. Internals are more independent, more reliant on own judgement, and more likely to accept information on its merit. In specific, IC is a person's view of his or her ability, decisions, and effort (internal) that can affect the actions without external influence or any circumstances [65,67]. A person with higher IC is more entrepreneurial than those with lower IC because he or she has a stronger achievement orientation, is more capable of handling the pressures and the uncertainties of business start-up, has a higher degree of belief in his or her abilities, and puts in more effort to influence the outcomes in any activities [68]. The individual can decide his or her destiny [68] due to the control over changing events [69]. In any failure or mistake, they are responsible for the consequence and will attempt to solve it, instead of looking for excuses for the failure. Robinson et al. [70] revealed that IC could lead to positive ATE. This study therefore hypothesised the following:

Hypothesis $\left(\mathbf{H}_{\mathbf{1 d}}\right)$. IC has a positive effect on ATE among the Asnaf millennials in Malaysia.

Risk-taking propensity (RP) refers to the tendency to take risks [71], accept doubt, and be responsible for the future [56]. According to Okudan and Rzasa [55], entrepreneurs are more likely to act on moderate risks in situations that they have some control over. Moderate and high risk-takers are more likely to be entrepreneurs [53]. Prior studies addressed the risk-taking propensity effect on ATE [59,72]. This study therefore hypothesised the following: 
Hypothesis $\left(\mathbf{H}_{1 \mathbf{e}}\right)$. RP has a positive effect on ATE among the Asnaf millennials in Malaysia.

\subsection{SUN and Entrepreneurial Intention}

SUN describes an individual's view of social pressures, which were set by a reference group, which is important to them in performing a behaviour and complying with others' views [73]. Prior studies revealed that a reference group of family, friends, and peers is the main support of a person's perception towards entrepreneurship [74]. Social norm has explained ENTI as a second determinant [74], which was positively influenced [75]. The following is the hypothesised prediction:

Hypothesis $\left.\mathbf{( H}_{\mathbf{2}}\right)$. SUN has a positive effect on ENTI for Asnaf millennials.

\section{Social Factors and SUN}

SUN is relevant to social factors that are affected by injunctive normative beliefs and descriptive normative beliefs. Injunctive normative beliefs are labelled as interpersonal influence while descriptive normative beliefs are labelled as cultural environment influence. This study included social factors, such as lifestyle integration and social networking.

Lifestyle integration (LI) refers to an individual's routine on the situation. For lifestyle, Claire [76] defined the scopes of lifestyle entrepreneurs as having a family-work balance, as well as making a living with something that a person enjoyed with an accommodating work schedule, such as working on a hobby and residing in a pleasant place.

Social networking (SN) is a set of ties that connects individuals [77] with family, friends, or acquaintances to acquire information that provides opportunity in identification and resources that they do not own, as well as influences the way people think for a new venture. Social ties include strong and weak ties that clarify the relationship with others to execute new venture engagement [33]. The value of a social network is essential because a person can gain information from wide range of networks [7] to establish and run a new venture [78]. Therefore, the following hypotheses are presented:

Hypothesis $\left(\mathbf{H}_{\mathbf{2}} \mathbf{)}\right.$. LI has a positive effect on SUN among the Asnaf millennials in Malaysia.

Hypothesis $\left(\mathbf{H}_{\mathbf{2 b}}\right)$. SN has a positive effect on SUN among the Asnaf millennials in Malaysia.

\section{4. $P B C$ and Entrepreneurial Intention}

$\mathrm{PBC}$ refers to an individual's comfort or struggle in executing a behaviour [73]. People with high $\mathrm{PBC}$ tend to perform the behaviour than those with low $\mathrm{PBC}$ who are less motivated to perform the behaviour [79]. Prior studies revealed that PBC was significant with ENTI [43,80]. When a person has higher $\mathrm{PBC}$, the person has a stronger desire for becoming self-employed. The following is the predicted hypothesis:

Hypothesis $\left(\mathbf{H}_{3}\right)$. PBC has a positive effect on ENTI for Asnaf millennials.

Resource, Opportunity Recognition, and PBC

Entrepreneurial activities can be defined as influences of the surrounding supportive environment. Past studies considered the element of a supportive environment, which was important in their studies [81]. A supportive environment is a mixture of factors in the setting that can develop or nurture entrepreneurship and business activities [65]. A supportive environment, such as entrepreneurial resource (RS), predominantly involves access to capital, as well as knowledge and training of nurturing business activities among entrepreneurs [82,83]. Entrepreneur RS includes an entrepreneur's own RSs and abilities [84]. Thus, RS is a crucial element that promotes entrepreneurial activity. Positive environmental influences can trigger the success of the entrepreneurial way of business [65]. 
Opportunity recognition $(\mathrm{OR})$ is the cognitive phenomena that considered the entrepreneurship decision process of a person [85]. An entrepreneur can identify chances based on various sources of information [86]. One of the entrepreneurship processes is identifying business opportunity within other new business start-ups. OR allows an entrepreneur to select a good idea before integrating it into a business concept, as well as internalising and practising all the skills [55]. Hunter [87] stated that an opportunity includes an individual's ability to recognise, discover, or construct patterns and concepts. Therefore, the following hypotheses are presented:

Hypothesis $\left(\mathbf{H}_{3 \mathbf{a}}\right)$. RS has a positive effect on PBC among the Asnaf millennials in Malaysia.

Hypothesis $\left(\mathbf{H}_{\mathbf{3 b}}\right)$. OR has a positive effect on PBC among the Asnaf millennials in Malaysia.

\subsection{Entrepreneurial Intention and Pre-Start-Up Behaviour}

ENTI refers to a person' motivation and plan in performing a behaviour. ENTI is described as the willingness to express entrepreneurial behaviour on a new venture to become self-employed or create a new establishment [88]. Several authors stated that intentions are the best predictors of a behaviour [47,73]. Gartner [89] revealed that planned behaviour is predicted by intention, which is rare and hard to observe. ENTI is the first stage for the creation of a long-term business [90]. The introduction of PRSB in the present study can create the decision for a new venture [34]. Past studies revealed that intention and behaviour have a positive relationship [16,91]. The following is the predicted hypothesis:

Hypothesis $\left(\mathbf{H}_{4}\right)$. ENTI has a positive effect on PRSB for Asnaf millennials.

\subsection{The Mediating Role of Entrepreneurial Intention}

Intention can intervene in the impacts of attitude and SUN on a behaviour while PBC has double parts in TPB [91]. In some cases, intention could influence the relationship between dependent variables and its antecedent $[91,92]$. Therefore, this study presented the following hypothesis:

Hypothesis $\left.\mathbf{( H}_{\mathbf{5}}\right)$. ENTI positively intervenes in the relationship of ATE, SUN, and PBC with PRSB among Asnaf millennials.

\subsection{The Moderating Role of Fungibility Issues}

Fungibility issues (FG) refers to self-control behaviour in reflecting human habits of misbehaving in financial management that might cause business failure. The level of self-control is not equal to all and not fixed in an individual since it may constantly fluctuate. Fungibility refers to the aid that is not used for the purpose intended by the donors. FG is closely related to the weakness of will in maxing out a person's income [93]. A person with a lower level of self-control has ENTI with no regulatory power over a behaviour [53]. FG is important as a moderator of the intention-action relationship since the least fungible can enhance and motivate the quality and availability of information pertaining to behaviour. This indicator either encourages or discourages the ability to control impulses, such as anxiety regarding failure, for self-control in financial situations. This study predicted that fungibility moderates the relationship between ENTI and PRSB as follows:

Hypothesis $\left.\mathbf{( H}_{\mathbf{6}}\right)$. FG negatively moderates the relationship between ENTI and PRSB among Asnaf millennials.

\section{Research Methodology}

This was a cross-sectional study, which collected quantitative data from Asnaf millennials in Kelantan using structured interviews. The reason for the choice is because the poverty rate is the highest in Kelantan compared to the other states in Peninsular Malaysia. Kelantan is also considered 
the most vulnerable to natural disasters, such as floods. The sample of this study was 2667 Asnaf who are eligible for monthly zakat (RM400) from Majlis Agama Islam Kelantan (MAIK). The study applied stratified random sampling method [94]. First, one territory of the state was chosen to represent the northeast region (i.e., Tumpat and Bachok) and southeast region (i.e., Jeli and Gua Musang) that cover rural areas and underdeveloped areas with inconsistent mean incomes, as well as the highest number of poor people $[95,96]$.

Second, the Asnaf in each area were randomly selected from the list of 2667 Asnaf collected from MAIK. This study considered the model of four people in the household, with one of them classified as a millennial between the age of 17 to 35, whereas Asnaf with no children were excluded from this study. This study contacted each household head prior to the interview. Once interviewees confirmed their willingness to participate, authors visited the location interviewees preferred and collected data through face-to-face structured interviews.

\subsection{Sample Size}

This study used G-Power version 3.1 to determine the sample size. This study used the power of 0.95 with an effect size of 0.15 in which the sample size was 194 for testing the model with 14 predictors. Hence, this study collected data from 310 Asnaf millennials to prevent any issues regarding a small sample size.

\subsection{Research Instrument}

ATE refers to the preference of an individual towards a specific thing and environment, such as emotions and actions, in which he or she holds something that would affect the formation of a positive attitude [97]. This study adopted six items from Linan [98] with minor modifications. SUN refers to the specific important influence of family and friends in the approval of performing a behaviour [85]. This study used six items from Baughn et al. [99] with minor modifications. $P B C$ is defined as the perception of a person on the effort of completing a task in performing a behaviour [100]. This study also adapted six items from Linan and Chen [100] with minor modifications. IN refers to the degree to which an individual tends to have a high preference for novel and original ideas [101]. Seven items were adopted from the Jackson Personality Inventory Scale with minor modifications. PP refers to the extent to which an individual looks for opportunities and acts according to the surroundings and persists in making a change [60]. A total of six items were taken from Bateman and Crants [60] with minor modifications. NA refers to an individual who is motivated to set challenging goals, excel in tasks, and motivated to achieve a significant accomplishment [101]. This study adopted five items from Lang and Fries [102] with minor alterations. IC refers to an individual's perception of their ability, decisions, and effort (internal) without external influence or any circumstances [67]. Six items were adopted from Rotter [67] and utilised by Gurol and Atsan [51] with minor modifications. RP refers to an individual's tendency to take risks, doubt, and burden of duty for the future [56]. Seven items were adopted from [50] with minor modifications.

$L I$ refers to individual practice based on the routine regarding familiar safety, upgrade in life, and interested in being their own boss [103]. Five items were adopted from Li et al. [104] and Crawford and Naar [105] with minor modification. SN refers to social engagement in developing and sustaining relationships with others who can boost their profession. This study adopted six items from Hoye et al. [106] with minor modifications. RS refers to the availability of RSs, such as access to capital, infrastructure, entrepreneurship program, time, and money for new venture creation. This study adopted six items from Baron and Tang [107] with minor alterations. RS refers to the numerous sources of information for the business opening. This study adopted six items from Ozgen and Baron [108] with minor modifications.

ENTI refers to the degree to which a person is determined to perform a behaviour. This study adopted six items from Linan and Chen [100] with minor modifications. FG refers to the possibilities of being impatient to use the working capital in generating income. This study used seven items from Stromback et al. [109] with minor changes. PRSB refers to the effort in new venture establishment on an 
array of activities in accomplishing a task prior to start-up. Ten items were adopted from LeBrasseur et al. [37] and Kautonen et al. [110] with minor modifications. Hence, this study used 108 items under 15 constructs. The measurement embarked in a series of item developments. All items presented in Appendix A.

\subsection{Common Method Variance (CMV)}

Two approaches to remedying CMV were implemented as suggested by Reio [111]. In the procedural design, the study provided balance for the order of the questions. The study used clear scale items to avoid bias. All responses should be given equivalent effort by avoiding complex wording, syntax, and double-barrelled questions. Clear instructions with definitions were given to prevent misunderstanding [112]. The amount of closed-ended questions should be more than open-ended questions. There were no right or wrong answers as the respondents should provide their honest opinion.

This study applied Harman's one-factor test to statistically check CMB [112]. All the items for all constructs were analysed using confirmatory factor analysis to determine whether the majority of the variance could be accounted by one general factor. The factor analysis of all items revealed a seven-factor solution that is in line with the number of constructs with a cumulative total variance of $40.3 \%$. They were predicted to clarify less than $50 \%$ of the variance. Therefore, CMB was not a problem.

\section{Data Analysis}

\subsection{Respondents' Profile}

Table 1 shows that the majority of respondents were females (179, $57.7 \%)$, whereas $131(42.3 \%)$ were male. Among the respondents, 91 respondents $(29.4 \%)$ were aged between 23 and 27, 87 respondents ( $28 \%)$ were aged from 33 to 37,83 respondents $(26.8 \%)$ were aged from 17 to 22 , and 49 respondents $(15.8 \%)$ were aged between 28 and 32 years old. There were 91 people (29.4) aged between 23 and 27 , followed by 87 people ( $28 \%$ ) aged from 33 to 37 , and 83 people ( $26.8 \%$ ) aged from 17 to 22 . There were fewer people aged from 28 to 32 in this study, with a total of 49 people (15.8\%). For the location, a relatively higher proportion of $146(47.1 \%)$ were from Tumpat, followed by 128 people (41.3) from Bachok. Jeli and Gua Musang exhibited low participation, with a total of 22 (7.1\%) and $14(4.5 \%)$, respectively. For respondents' education level, the majority of them, with a total of 200 people $(64.5 \%)$, completed secondary school, followed by 90 respondents $(29 \%)$ who completed tertiary education, and 19 people $(6.1 \%)$ who obtained primary school education while one person $(0.3 \%)$ had no formal education. Most of the respondents, with a total of 169 (54.5\%), were single, whereas the remaining $134(43.2 \%)$ were married, and only seven respondents $(2.3 \%)$ were divorced.

Table 1. Descriptive statistics on respondents' Profile.

\begin{tabular}{cccccc}
\hline Category & Frequency & Percent & Category & Frequency & Percent \\
\hline Gender & & & Location & \\
Male & 131 & $42.3 \%$ & Bachok & 128 & $41.3 \%$ \\
Female & 179 & $57.7 \%$ & Tumpat & 146 & $47.1 \%$ \\
& & Jeli & 22 & $7.1 \%$ \\
Age Groups & & Gua Musang & 14 & $4.5 \%$ \\
17 to 22 years & 83 & $26.8 \%$ & Total & 310 & $100.0 \%$ \\
23 to 27 years & 91 & $29.4 \%$ & Education & & \\
28 to 32 years & 49 & $15.8 \%$ & No formal education & 1 & $0.3 \%$ \\
33 to 37 years & 87 & $28.1 \%$ & Primary School & 19 & $6.1 \%$ \\
Total & 310 & $100.0 \%$ & Secondary school & 200 & $64.5 \%$ \\
& & & Upper Secondary school & 35 & $11.3 \%$ \\
Marital Status & 169 & 54.5 & Tertiary education & 54 & $17.4 \%$ \\
Single & 134 & 43.2 & Others & 1 & $0.3 \%$ \\
Married & 7 & 2.3 & Total & 310 & 100.0 \\
Divorced & 310 & 100.0 & & & \\
Total & & &
\end{tabular}




\subsection{Validity and Reliability}

Table 2 shows that all Cronbach's $\alpha$ for the indicators were more than 0.7 , which confirmed the internal consistency reliability [113]. The results were further validated using composite reliabilities (CRs) that were more than 0.8 for all items [114]. For indicator loadings, all of the items scored more than 0.7 , which confirmed their reliability [115].

Table 2. Validity and reliability.

\begin{tabular}{|c|c|c|c|c|c|}
\hline Perspective & $\begin{array}{l}\text { Number of } \\
\text { Items }\end{array}$ & $\begin{array}{c}\text { Cronbach's } \\
\text { Alpha }\end{array}$ & $\begin{array}{l}\text { Composite } \\
\text { Reliability }\end{array}$ & $\begin{array}{l}\text { Average Variance } \\
\text { Extracted }\end{array}$ & $\begin{array}{c}\text { Variance Inflation } \\
\text { Factor }\end{array}$ \\
\hline ATE & 4 & 0.856 & 0.903 & 0.699 & 1.658 \\
\hline IN & 5 & 0.865 & 0.902 & 0.649 & 1.59 \\
\hline $\mathrm{PP}$ & 4 & 0.775 & 0.855 & 0.597 & 1.441 \\
\hline NA & 4 & 0.799 & 0.869 & 0.625 & 1.878 \\
\hline IC & 4 & 0.752 & 0.844 & 0.574 & 1.45 \\
\hline $\mathrm{RP}$ & 5 & 0.846 & 0.89 & 0.618 & 1.766 \\
\hline SUN & 3 & 0.815 & 0.891 & 0.731 & 1.238 \\
\hline LI & 5 & 0.864 & 0.9 & 0.644 & 1.842 \\
\hline $\mathrm{SN}$ & 4 & 0.873 & 0.912 & 0.723 & 1.842 \\
\hline PBC & 5 & 0.889 & 0.919 & 0.695 & 1.801 \\
\hline RS & 5 & 0.856 & 0.897 & 0.636 & 2.001 \\
\hline OR & 5 & 0.891 & 0.92 & 0.698 & 2.001 \\
\hline ENTI & 4 & 0.92 & 0.944 & 0.807 & 1.002 \\
\hline FG & 4 & 0.945 & 0.96 & 0.856 & 1.016 \\
\hline PRSB & 6 & 0.942 & 0.954 & 0.775 & - \\
\hline
\end{tabular}

Notes: ATE: Attitude Towards Entrepreneurship; IN: Innovativeness; PP: Proactive Personality; NA: Need for Achievement; IC: Internal Locus of Control; RP: Risk-Taking Propensity; SUN: Subjective Norms; LI: Lifestyle Integration; SN: Social Networking; PBC: Perceived Behavioural Control; RS: Resource; OR: Opportunity Recognition; ENTI: Entrepreneurial Intention; FG: Fungibility Issues; PRSB: Pre-start-up Behaviour.

This study used factor loadings and average variance extracted (AVE) to determine the convergent validity. Table 3 reveals that the factor loadings for all indicators were more than 0.708 , which can explain at least $50 \%$ of the indicators' variance, except for two indicators. They are acceptable as they are considered close enough to 0.708 , with the amount of 0.704 and 0.706 for INN2 and PP2, respectively. These two indicators were accepted since their AVEs were more than 0.5. The AVE of all constructs was between 0.587 and 0.839 , which is above the 0.5 thresholds, indicating that the measurement scales had adequate measurement validity [100]. The AVE of each perspective was higher than 0.5 , which exhibited satisfactory convergent validity.

The cross-loadings test discriminant validity showed that there is one item that has higher cross-loadings than the other loadings. These results verified the discriminant validity [115]. According to the Fornell-Larcker principle, a latent variable splits more variance with its indicators compared to other latent variables. According to Fornell and Larcker [116], the average value of each latent variable should be more than the highest squared correlation with any other latent variables. Table 3 shows the matrix of latent variable correlations in which the diagonal elements are the squared values of AVE. Discriminant validity holds when the AVE is greater than the shared value of other variances. Table 3 presents that all the squared values of AVE were more than the squared correlation of the same latent variable. Hence, the finding has good discriminant validity. The tests confirmed the model's reliability and validity, as well as the explanatory power of the relationships between itemised variables. 
Table 3. Discriminant validity.

\begin{tabular}{|c|c|c|c|c|c|c|c|c|c|c|c|c|c|c|c|}
\hline Perspective & ATE & IN & PP & NA & IC & $\mathbf{R P}$ & SUN & LI & SN & PBC & RS & OR & ENTI & FG & PRSB \\
\hline ATE-1 & 0.809 & 0.396 & 0.323 & 0.366 & 0.288 & 0.332 & 0.253 & 0.423 & 0.381 & 0.490 & 0.282 & 0.420 & 0.442 & 0.082 & 0.381 \\
\hline ATE-2 & 0.852 & 0.403 & 0.347 & 0.464 & 0.360 & 0.363 & 0.235 & 0.408 & 0.373 & 0.499 & 0.349 & 0.417 & 0.478 & 0.037 & 0.328 \\
\hline ATE-3 & 0.859 & 0.432 & 0.318 & 0.452 & 0.324 & 0.354 & 0.367 & 0.470 & 0.445 & 0.539 & 0.401 & 0.488 & 0.515 & 0.040 & 0.395 \\
\hline IN-1 & 0.443 & 0.777 & 0.441 & 0.489 & 0.345 & 0.409 & 0.237 & 0.537 & 0.512 & 0.491 & 0.452 & 0.517 & 0.478 & -0.095 & 0.475 \\
\hline IN-2 & 0.394 & 0.799 & 0.348 & 0.399 & 0.283 & 0.324 & 0.247 & 0.439 & 0.413 & 0.445 & 0.372 & 0.442 & 0.463 & -0.086 & 0.381 \\
\hline IN-3 & 0.410 & 0.843 & 0.346 & 0.394 & 0.233 & 0.341 & 0.292 & 0.437 & 0.416 & 0.452 & 0.396 & 0.454 & 0.475 & -0.096 & 0.432 \\
\hline IN-4 & 0.374 & 0.830 & 0.384 & 0.437 & 0.308 & 0.404 & 0.351 & 0.474 & 0.440 & 0.478 & 0.367 & 0.424 & 0.477 & -0.076 & 0.391 \\
\hline PP-1 & 0.340 & 0.443 & 0.816 & 0.435 & 0.268 & 0.316 & 0.212 & 0.353 & 0.446 & 0.397 & 0.261 & 0.309 & 0.336 & -0.063 & 0.291 \\
\hline PP-2 & 0.283 & 0.305 & 0.775 & 0.287 & 0.205 & 0.225 & 0.210 & 0.263 & 0.357 & 0.319 & 0.209 & 0.240 & 0.281 & 0.043 & 0.184 \\
\hline PP-3 & 0.340 & 0.419 & 0.785 & 0.447 & 0.279 & 0.330 & 0.174 & 0.407 & 0.415 & 0.364 & 0.273 & 0.382 & 0.365 & -0.078 & 0.308 \\
\hline PP-4 & 0.262 & 0.270 & 0.710 & 0.296 & 0.204 & 0.287 & 0.164 & 0.242 & 0.334 & 0.241 & 0.191 & 0.183 & 0.209 & 0.051 & 0.123 \\
\hline NA-1 & 0.368 & 0.461 & 0.389 & 0.712 & 0.338 & 0.403 & 0.298 & 0.425 & 0.429 & 0.432 & 0.326 & 0.403 & 0.398 & -0.092 & 0.364 \\
\hline NA-2 & 0.385 & 0.392 & 0.399 & 0.824 & 0.345 & 0.422 & 0.254 & 0.418 & 0.471 & 0.451 & 0.404 & 0.422 & 0.371 & -0.037 & 0.267 \\
\hline NA-3 & 0.441 & 0.399 & 0.391 & 0.813 & 0.377 & 0.560 & 0.328 & 0.489 & 0.453 & 0.528 & 0.432 & 0.470 & 0.465 & -0.023 & 0.414 \\
\hline NA-4 & 0.453 & 0.443 & 0.354 & 0.807 & 0.336 & 0.408 & 0.200 & 0.482 & 0.453 & 0.481 & 0.392 & 0.467 & 0.413 & -0.065 & 0.322 \\
\hline IC-1 & 0.285 & 0.239 & 0.194 & 0.290 & 0.742 & 0.372 & 0.207 & 0.288 & 0.218 & 0.235 & 0.171 & 0.262 & 0.270 & -0.004 & 0.193 \\
\hline IC-3 & 0.313 & 0.249 & 0.251 & 0.324 & 0.740 & 0.343 & 0.208 & 0.325 & 0.314 & 0.324 & 0.216 & 0.325 & 0.266 & 0.007 & 0.174 \\
\hline IC-4 & 0.285 & 0.239 & 0.186 & 0.317 & 0.736 & 0.386 & 0.140 & 0.295 & 0.252 & 0.264 & 0.197 & 0.322 & 0.255 & -0.064 & 0.238 \\
\hline RP-1 & 0.359 & 0.269 & 0.212 & 0.407 & 0.377 & 0.780 & 0.214 & 0.378 & 0.438 & 0.471 & 0.415 & 0.394 & 0.367 & 0.068 & 0.278 \\
\hline RP-2 & 0.298 & 0.306 & 0.210 & 0.375 & 0.481 & 0.754 & 0.266 & 0.408 & 0.441 & 0.415 & 0.410 & 0.428 & 0.356 & 0.035 & 0.347 \\
\hline RP-3 & 0.400 & 0.455 & 0.390 & 0.539 & 0.453 & 0.811 & 0.321 & 0.480 & 0.507 & 0.525 & 0.390 & 0.510 & 0.471 & -0.116 & 0.359 \\
\hline RP-4 & 0.352 & 0.361 & 0.371 & 0.499 & 0.411 & 0.801 & 0.248 & 0.473 & 0.490 & 0.475 & 0.444 & 0.488 & 0.417 & 0.007 & 0.400 \\
\hline RP-5 & 0.288 & 0.376 & 0.274 & 0.392 & 0.320 & 0.782 & 0.229 & 0.401 & 0.443 & 0.456 & 0.415 & 0.438 & 0.392 & 0.012 & 0.349 \\
\hline SUN-1 & 0.312 & 0.306 & 0.192 & 0.295 & 0.272 & 0.297 & 0.811 & 0.310 & 0.370 & 0.360 & 0.311 & 0.300 & 0.335 & 0.027 & 0.294 \\
\hline SUN-2 & 0.282 & 0.279 & 0.223 & 0.287 & 0.234 & 0.286 & 0.879 & 0.333 & 0.340 & 0.372 & 0.315 & 0.317 & 0.396 & -0.025 & 0.355 \\
\hline SUN-3 & 0.273 & 0.304 & 0.215 & 0.288 & 0.181 & 0.256 & 0.873 & 0.314 & 0.326 & 0.370 & 0.313 & 0.298 & 0.362 & -0.002 & 0.318 \\
\hline LI-1 & 0.434 & 0.386 & 0.256 & 0.373 & 0.248 & 0.330 & 0.235 & 0.750 & 0.469 & 0.451 & 0.441 & 0.467 & 0.478 & 0.016 & 0.402 \\
\hline LI-2 & 0.405 & 0.506 & 0.323 & 0.528 & 0.374 & 0.448 & 0.301 & 0.788 & 0.551 & 0.468 & 0.478 & 0.568 & 0.570 & -0.108 & 0.433 \\
\hline LI-3 & 0.407 & 0.447 & 0.305 & 0.456 & 0.392 & 0.467 & 0.218 & 0.794 & 0.542 & 0.492 & 0.470 & 0.575 & 0.522 & -0.216 & 0.427 \\
\hline LI-4 & 0.408 & 0.476 & 0.333 & 0.430 & 0.363 & 0.472 & 0.274 & 0.830 & 0.563 & 0.514 & 0.533 & 0.578 & 0.551 & -0.131 & 0.449 \\
\hline LI-5 & 0.458 & 0.494 & 0.413 & 0.501 & 0.370 & 0.469 & 0.404 & 0.846 & 0.577 & 0.519 & 0.537 & 0.588 & 0.572 & -0.041 & 0.453 \\
\hline
\end{tabular}


Table 3. Cont

\begin{tabular}{|c|c|c|c|c|c|c|c|c|c|c|c|c|c|c|c|}
\hline Perspective & ATE & IN & PP & NA & IC & $\mathbf{R P}$ & SUN & LI & SN & РBC & RS & OR & ENTI & FG & PRSB \\
\hline SN-1 & 0.442 & 0.431 & 0.442 & 0.523 & 0.357 & 0.508 & 0.320 & 0.545 & 0.826 & 0.576 & 0.475 & 0.595 & 0.494 & 0.045 & 0.481 \\
\hline $\mathrm{SN}-2$ & 0.413 & 0.503 & 0.435 & 0.492 & 0.332 & 0.506 & 0.317 & 0.569 & 0.848 & 0.549 & 0.553 & 0.607 & 0.544 & 0.039 & 0.477 \\
\hline SN-3 & 0.348 & 0.466 & 0.405 & 0.440 & 0.301 & 0.464 & 0.303 & 0.560 & 0.843 & 0.505 & 0.547 & 0.581 & 0.503 & 0.036 & 0.476 \\
\hline PBC-1 & 0.524 & 0.361 & 0.269 & 0.427 & 0.284 & 0.428 & 0.375 & 0.499 & 0.499 & 0.776 & 0.524 & 0.559 & 0.540 & 0.108 & 0.517 \\
\hline PBC-2 & 0.554 & 0.526 & 0.459 & 0.554 & 0.302 & 0.496 & 0.413 & 0.554 & 0.646 & 0.803 & 0.543 & 0.585 & 0.565 & 0.020 & 0.529 \\
\hline PBC-3 & 0.457 & 0.472 & 0.318 & 0.479 & 0.314 & 0.518 & 0.305 & 0.473 & 0.512 & 0.819 & 0.530 & 0.543 & 0.442 & 0.023 & 0.480 \\
\hline PBC-4 & 0.494 & 0.499 & 0.330 & 0.462 & 0.308 & 0.488 & 0.341 & 0.447 & 0.496 & 0.879 & 0.482 & 0.557 & 0.424 & 0.098 & 0.497 \\
\hline RS-1 & 0.422 & 0.376 & 0.232 & 0.440 & 0.280 & 0.431 & 0.304 & 0.521 & 0.593 & 0.538 & 0.753 & 0.621 & 0.573 & 0.058 & 0.527 \\
\hline RS-2 & 0.342 & 0.464 & 0.274 & 0.410 & 0.242 & 0.419 & 0.291 & 0.524 & 0.571 & 0.518 & 0.846 & 0.602 & 0.443 & 0.002 & 0.423 \\
\hline RS-3 & 0.332 & 0.427 & 0.241 & 0.392 & 0.144 & 0.407 & 0.268 & 0.474 & 0.503 & 0.513 & 0.797 & 0.520 & 0.470 & -0.06 & 0.441 \\
\hline RS-4 & 0.359 & 0.330 & 0.273 & 0.396 & 0.304 & 0.440 & 0.334 & 0.517 & 0.533 & 0.508 & 0.833 & 0.554 & 0.502 & 0.018 & 0.469 \\
\hline RS-5 & 0.214 & 0.329 & 0.193 & 0.316 & 0.172 & 0.395 & 0.257 & 0.407 & 0.422 & 0.434 & 0.753 & 0.510 & 0.405 & 0.001 & 0.428 \\
\hline OR-1 & 0.429 & 0.456 & 0.311 & 0.430 & 0.335 & 0.471 & 0.221 & 0.560 & 0.540 & 0.564 & 0.558 & 0.794 & 0.530 & -0.046 & 0.522 \\
\hline OR-2 & 0.481 & 0.464 & 0.319 & 0.446 & 0.375 & 0.457 & 0.282 & 0.569 & 0.613 & 0.575 & 0.556 & 0.835 & 0.556 & 0.049 & 0.537 \\
\hline OR-3 & 0.424 & 0.495 & 0.268 & 0.496 & 0.366 & 0.476 & 0.330 & 0.591 & 0.576 & 0.563 & 0.580 & 0.829 & 0.633 & -0.047 & 0.577 \\
\hline OR-4 & 0.426 & 0.487 & 0.293 & 0.482 & 0.346 & 0.466 & 0.357 & 0.565 & 0.597 & 0.597 & 0.639 & 0.855 & 0.624 & -0.013 & 0.594 \\
\hline ENTI -1 & 0.482 & 0.563 & 0.325 & 0.478 & 0.345 & 0.443 & 0.354 & 0.598 & 0.570 & 0.545 & 0.552 & 0.666 & 0.885 & -0.057 & 0.605 \\
\hline ENTI -2 & 0.543 & 0.532 & 0.402 & 0.476 & 0.345 & 0.461 & 0.386 & 0.629 & 0.575 & 0.552 & 0.533 & 0.639 & 0.904 & -0.011 & 0.616 \\
\hline ENTI -3 & 0.515 & 0.478 & 0.343 & 0.455 & 0.364 & 0.474 & 0.382 & 0.593 & 0.552 & 0.530 & 0.532 & 0.593 & 0.909 & -0.024 & 0.586 \\
\hline ENTI -4 & 0.529 & 0.544 & 0.338 & 0.469 & 0.336 & 0.463 & 0.411 & 0.604 & 0.587 & 0.547 & 0.553 & 0.657 & 0.895 & -0.017 & 0.606 \\
\hline FG-1 & 0.088 & -0.056 & 0.004 & -0.011 & -0.021 & 0.025 & 0.019 & -0.058 & 0.085 & 0.113 & 0.048 & 0.035 & -0.012 & 0.938 & 0.071 \\
\hline FG-2 & 0.038 & -0.112 & -0.017 & -0.077 & -0.062 & -0.033 & -0.001 & -0.13 & 0.055 & 0.029 & -0.019 & -0.009 & -0.01 & 0.916 & 0.027 \\
\hline FG-3 & 0.057 & -0.149 & -0.031 & -0.087 & -0.025 & -0.033 & -0.06 & -0.154 & 0.058 & 0.038 & -0.06 & -0.03 & -0.074 & 0.918 & 0.052 \\
\hline FG-4 & 0.031 & -0.125 & -0.05 & -0.101 & -0.015 & 0.000 & 0.032 & -0.1 & 0.053 & 0.058 & 0.024 & -0.017 & -0.013 & 0.928 & 0.054 \\
\hline PRSB-1 & 0.394 & 0.400 & 0.233 & 0.366 & 0.242 & 0.356 & 0.302 & 0.428 & 0.533 & 0.537 & 0.511 & 0.559 & 0.548 & 0.087 & 0.877 \\
\hline PRSB-2 & 0.421 & 0.512 & 0.312 & 0.446 & 0.309 & 0.467 & 0.369 & 0.536 & 0.570 & 0.600 & 0.548 & 0.659 & 0.655 & -0.012 & 0.901 \\
\hline PRSB-3 & 0.351 & 0.465 & 0.274 & 0.375 & 0.291 & 0.402 & 0.307 & 0.466 & 0.523 & 0.531 & 0.506 & 0.592 & 0.536 & 0.067 & 0.866 \\
\hline PRSB-4 & 0.374 & 0.423 & 0.254 & 0.365 & 0.248 & 0.357 & 0.371 & 0.464 & 0.484 & 0.550 & 0.479 & 0.558 & 0.578 & 0.085 & 0.870 \\
\hline PRSB-5 & 0.409 & 0.477 & 0.265 & 0.382 & 0.238 & 0.393 & 0.339 & 0.484 & 0.505 & 0.530 & 0.506 & 0.615 & 0.635 & 0.016 & 0.898 \\
\hline
\end{tabular}


Table 3. Cont.

\begin{tabular}{|c|c|c|c|c|c|c|c|c|c|c|c|c|c|c|c|}
\hline Perspective & ATE & IN & PP & NA & IC & $\mathbf{R P}$ & SUN & LI & SN & PBC & RS & OR & ENTI & FG & PRSB \\
\hline \multicolumn{16}{|c|}{ Heterotrait-Monotrait Ratio (HTMT) } \\
\hline ATE & - & & & & & & & & & & & & & & \\
\hline IN & 0.573 & - & & & & & & & & & & & & & \\
\hline NA & 0.628 & 0.643 & 0.605 & - & & & & & & & & & & & \\
\hline IC & 0.488 & 0.437 & 0.402 & 0.568 & - & & & & & & & & & & \\
\hline $\mathrm{RP}$ & 0.506 & 0.523 & 0.454 & 0.681 & 0.650 & - & & & & & & & & & \\
\hline SUN & 0.403 & 0.416 & 0.309 & 0.424 & 0.341 & 0.391 & - & & & & & & & & \\
\hline $\mathrm{SN}$ & 0.561 & 0.635 & 0.610 & 0.685 & 0.471 & 0.684 & 0.472 & 0.771 & - & & & & & & \\
\hline PBC & 0.712 & 0.641 & 0.510 & 0.706 & 0.459 & 0.685 & 0.502 & 0.689 & 0.745 & - & & & & & \\
\hline RS & 0.486 & 0.558 & 0.369 & 0.591 & 0.355 & 0.619 & 0.437 & 0.707 & 0.753 & 0.720 & - & & & & \\
\hline OR & 0.603 & 0.641 & 0.433 & 0.660 & 0.523 & 0.661 & 0.419 & 0.787 & 0.809 & 0.781 & 0.806 & - & & & \\
\hline ENTI & 0.648 & 0.660 & 0.455 & 0.608 & 0.463 & 0.577 & 0.492 & 0.751 & 0.703 & 0.663 & 0.677 & 0.785 & - & & \\
\hline FG & 0.065 & 0.131 & 0.092 & 0.092 & 0.051 & 0.075 & 0.041 & 0.152 & 0.071 & 0.083 & 0.058 & 0.057 & 0.042 & - & \\
\hline PRSB & 0.497 & 0.559 & 0.342 & 0.497 & 0.358 & 0.492 & 0.429 & 0.595 & 0.641 & 0.675 & 0.639 & 0.736 & 0.718 & 0.068 & - \\
\hline
\end{tabular}

Fornell and Larcker Criterion

\begin{tabular}{|c|c|c|c|c|c|c|c|c|c|c|c|c|c|c|c|}
\hline ATE & 0.836 & & & & & & & & & & & & & & \\
\hline IN & 0.496 & 0.806 & & & & & & & & & & & & & \\
\hline PP & 0.400 & 0.474 & 0.772 & & & & & & & & & & & & \\
\hline NA & 0.524 & 0.535 & 0.483 & 0.79 & & & & & & & & & & & \\
\hline IC & 0.393 & 0.355 & 0.313 & 0.441 & 0.758 & & & & & & & & & & \\
\hline$R P$ & 0.437 & 0.453 & 0.377 & 0.570 & 0.521 & 0.786 & & & & & & & & & \\
\hline SUN & 0.338 & 0.346 & 0.246 & 0.339 & 0.268 & 0.327 & 0.855 & & & & & & & & \\
\hline LI & 0.527 & 0.580 & 0.417 & 0.576 & 0.437 & 0.547 & 0.373 & 0.802 & & & & & & & \\
\hline SN & 0.490 & 0.554 & 0.507 & 0.571 & 0.383 & 0.592 & 0.404 & 0.676 & 0.850 & & & & & & \\
\hline PBC & 0.625 & 0.565 & 0.434 & 0.601 & 0.379 & 0.599 & 0.429 & 0.610 & 0.666 & 0.834 & & & & & \\
\hline RS & 0.424 & 0.486 & 0.306 & 0.494 & 0.289 & 0.526 & 0.366 & 0.617 & 0.663 & 0.633 & 0.797 & & & & \\
\hline OR & 0.527 & 0.566 & 0.370 & 0.559 & 0.430 & 0.577 & 0.357 & 0.694 & 0.717 & 0.699 & 0.707 & 0.835 & & & \\
\hline ENTI & 0.576 & 0.589 & 0.392 & 0.523 & 0.387 & 0.513 & 0.427 & 0.675 & 0.636 & 0.605 & 0.604 & 0.711 & 0.898 & & \\
\hline FG & 0.063 & -0.113 & -0.024 & -0.067 & -0.028 & -0.004 & -0.001 & -0.111 & 0.071 & 0.074 & 0.006 & -0.001 & -0.030 & 0.925 & \\
\hline PRSB & 0.447 & 0.510 & 0.303 & 0.434 & 0.301 & 0.440 & 0.378 & 0.540 & 0.585 & 0.621 & 0.576 & 0.677 & 0.672 & 0.060 & 0.881 \\
\hline
\end{tabular}

Notes: ATE: Attitude Towards Entrepreneurship; IN: Innovativeness; PP: Proactive Personality; NA: Need for Achievement; IC: Internal Locus of Control; RP: Risk-Taking Propensity; SUN: Subjective Norms; LI: Lifestyle Integration; SN: Social Networking; PBC: Perceived Behavioural Control; RS: Resource; OR: Opportunity Recognition; ENTI: Entrepreneurial Intention; FG: Fungibility Issues; PRSB: Pre-start-up Behaviour. 


\subsection{Structural Model}

This study examined the data using structural equation modelling (SmartPLS 3.2.7 statistical package) to determine the theoretical interdependencies between ATE, SUN, PBC, ENTI, FG, and PRSB (see Figure 1). Structural equation modelling is favoured in analysing the mediating variable and moderating variables as the relevant paths are directly verified and issues, such as measurement error and feedback, are included in the model [117]. This study performed path analysis in PLS for hypotheses testing.

Table 4 shows the outcome of the structural path analysis. The $r^{2}$ value of 0.372 with $37.2 \%$ has moderate explanatory power of the variation in ATE among Asnaf millennials in explaining IN, PP, NA, IC, and RP. The $Q^{2}$ value of 0.239 indicates a medium predictive relevance of IN, PP, NA, IC, and RP on ATE among the Asnaf millennials. The $r^{2}$ value of 0.182 indicates a weak explanatory power of the variation in SUN among the Asnaf millennials in explaining LI and SN. LI and SN have a small predictive relevance on SUN among the Asnaf millennials, with a $Q^{2}$ value of 0.122 . There is a large explanatory power of the variation in PBC among the Asnaf millennials in explaining RS and RS, with an $r^{2}$ value of 0.529 . The $Q^{2}$ value of 0.339 indicates a medium predictive relevance of RS and RS on PBC among Asnaf millennials. The $r^{2}$ value of 0.456 indicates a moderate explanatory power of the variation in ENTI among Asnaf millennials in explaining ATE, SUN, and PBC. The $Q^{2}$ value of 0.342 indicates a medium predictive relevance of ATE, SUN, and PBC on ENTI among Asnaf millennials. The $r^{2}$ value of 0.527 indicates a large explanatory power of the variation in PRSB among the Asnaf millennials in explaining ENTI. The $Q^{2}$ value of 0.329 indicates a medium predictive relevance of ENTI on PRSB among the Asnaf millennials.

Table 4 shows IN has a positive effect on ATE among the Asnaf millennials, which suggests that Asnaf millennials with a relatively higher level of IN have a comparatively higher level of ATE. Moreover, the path coefficient of the structural model reveals that the coefficient value for IN on ATE is 0.233 and the $p$-value is $0.000\left(\mathrm{H}_{1 \mathrm{a}}\right)$. This result confirms that the effect of IN on ATE is statistically significant. The effect size of 0.055 reveals that IN has a relatively small effect on ATE among the Asnaf millennials. Finally, this study used a blindfolding procedure to determine the predictive relevance. The $q^{2}$ value of 0.405 is more than 0 , which reveals that IN has sufficient predictive relevance on ATE among the Asnaf millennials. The path coefficient value for PP on ATE is 0.098 and the $p$-value is 0.035 $\left(\mathrm{H}_{1 \mathrm{~b}}\right)$, which reveals that PP has a positive and significant effect on ATE. PP has a relatively small effect on ATE with an $f^{2}$ value of 0.011. Finally, PP has a medium predictive relevance on ATE with a $q^{2}$ value of 0.139 . The path coefficient value for NA on ATE is 0.247 and the $p$-value is $0.001\left(\mathrm{H}_{1 \mathrm{c}}\right)$, in which ATE has a positive and significant effect on ATE. NA has a small effect on ATE with an $f^{2}$ value of 0.052 . The $q^{2}$ value of 0.209 is more than 0 in which NA has a medium predictive relevance on ATE. IC has a path coefficient value of 0.124 on ATE and the $p$-value is $0.009\left(\mathrm{H}_{1 \mathrm{~d}}\right)$ in which IC has positive and significant effect on ATE. IC has a fairly small effect on ATE with an $f^{2}$ value of 0.017 , and IC has low predictive relevance with a $q^{2}$ value of 0.088 on ATE. Finally, the path coefficient value for RP on ATE is 0.089 and the $p$-value is $0.100\left(\mathrm{H}_{1 \mathrm{e}}\right)$ in which RT has a positive effect on ATE but is not statistically significant. RP has a small effect on ATE with an $f^{2}$ value of 0.007 and a $q^{2}$ value of 0.305 in which RT has a medium predictive relevance on ATE.

Table 4 shows the path coefficient value for LI on SUN is 0.185 and the $p$-value is $0.006\left(\mathrm{H}_{2 \mathrm{a}}\right)$ in which L1 has positive and significant effects on SUN. L1 has a small effect on SUN with an $f^{2}$ value of 0.023 and a $q^{2}$ value of 0.597 in which L1 has a medium predictive relevance on SUN. The path coefficient of the structural model reveals that the coefficient value for SN on SUN is 0.279 and the $p$-value is $0.000\left(\mathrm{H}_{2 b}\right)$ in which SN has positive and significant effects on SUN. SN has a small effect on SUN with an $f^{2}$ value of 0.052 and a $q^{2}$ value of 0.773 in which $S N$ has a high predictive relevance on SUN. Table 4 shows the path coefficient value for RS on PBC is 0.279 and the $p$-value is $0.000\left(\mathrm{H}_{3 \mathrm{a}}\right)$ in which RS has a positive and significant effect on PBC. RS has a small effect on PBC with an $f^{2}$ value of 0.082 and a $q^{2}$ value of 0.179 that is more than 0 in which RS has a low predictive relevance on PBC. The path coefficient for OR on PBC is 0.502 and the $p$-value is $0.000\left(\mathrm{H}_{3 \mathrm{~b}}\right)$ in which OR has positive and 
significant effects. OR has a medium effect on PBC with an $f^{2}$ value of 0.267 and a $q^{2}$ value of 0.375 , which is more than 0 , in which OR has a medium predictive relevance on PBC.

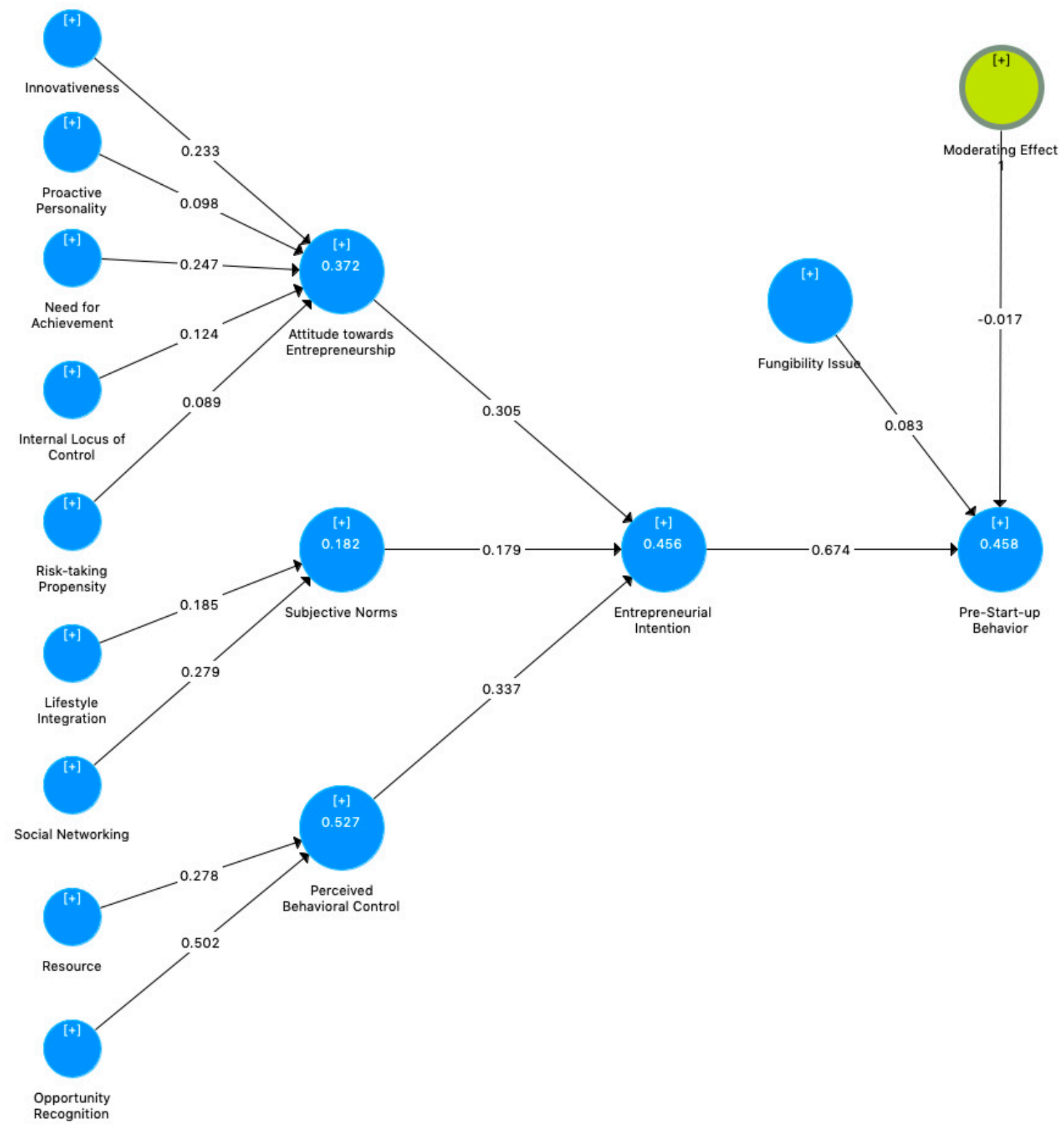

Figure 1. Research model.

Table 4 reveals that there is a positive effect between ATE and ENTI among the Asnaf millennials. ATE has a path coefficient value of 0.305 on ENTI and the $p$-value is $0.000\left(\mathrm{H}_{1}\right)$ in which ATE has a significant effect. ATE has a medium effect on ENTI with an $f^{2}$ value of 0.103 and a $q^{2}$ value of 0.247 , which is more than 0 , in which ATE has a medium predictive relevance on ENTI. Moreover, SUN has a path coefficient value of 0.179 on ENTI and the $p$-value is $0.000\left(\mathrm{H}_{2}\right)$ in which SUN has positive and significant effects. SUN has a medium effect on ENTI, with an $f^{2}$ value of 0.048 and a $q^{2}$ value of 0.156 , which is more than 0 , in which SUN has a low predictive relevance on ENTI. Finally, PBC has a path coefficient value of 0.337 on ENTI and the $p$-value is $0.000\left(\mathrm{H}_{3}\right)$ in which PBC has positive and significant effects. PBC has a medium effect on ENTI, with an $f^{2}$ value of 0.116 and the $q^{2}$ value is 0.361 , which is more than 0 , in which PBC has a low predictive relevance for ENTI. The findings 
revealed that there is a positive effect between ENTI and PRSB among the Asnaf millennials. ENTI has a path coefficient value of 0.674 on PRSB and the $p$-value is $0.000\left(\mathrm{H}_{4}\right)$ in which ENTI has a significant effect. ENTI has a large effect on PRSB with an $f^{2}$ value of 0.837 and a $q^{2}$ value of 0.766 , which is more than 0 , in which ENTI has a high predictive relevance on PRSB.

Table 4. Path coefficient parameters of the structural model.

\begin{tabular}{|c|c|c|c|c|c|c|c|c|c|}
\hline Hypo. & Causal Path & $\beta$ & $t$ & Sig. & Decision & $r^{2}$ & $f^{2}$ & $Q^{2}$ & $q^{2}$ \\
\hline \multicolumn{10}{|c|}{ Factors effecting Attitude Towards Entrepreneurship } \\
\hline$H 1 a$ & IN $->$ ATE & 0.233 & 3.678 & 0.000 & Supported & \multirow{5}{*}{0.372} & 0.055 & \multirow{5}{*}{0.239} & 0.405 \\
\hline$H 1 b$ & PP $->$ ATE & 0.098 & 1.81 & 0.035 & Supported & & 0.011 & & 0.139 \\
\hline H1c & NA $->$ ATE & 0.247 & 3.287 & 0.001 & Supported & & 0.052 & & 0.209 \\
\hline H1d & IC $->$ ATE & 0.124 & 2.359 & 0.009 & Supported & & 0.017 & & 0.088 \\
\hline H1e & RP $->$ ATE & 0.089 & 1.283 & 0.100 & Not Supported & & 0.007 & & 0.305 \\
\hline \multicolumn{10}{|c|}{ Factors effecting Subjective Norms } \\
\hline$H 2 a$ & LI $\rightarrow$ SUN & 0.185 & 2.498 & 0.006 & Supported & \multirow{2}{*}{0.182} & 0.023 & \multirow{2}{*}{0.122} & 0.597 \\
\hline$H 2 b$ & SN $->$ SUN & 0.279 & 4.129 & 0.000 & Supported & & 0.052 & & 0.773 \\
\hline \multicolumn{10}{|c|}{ Factors effecting Perceived Behavioural Control } \\
\hline$H 3 a$ & RS $->$ PBC & 0.278 & 4.989 & 0.000 & Supported & \multirow[b]{2}{*}{0.529} & 0.082 & \multirow[b]{2}{*}{0.339} & 0.179 \\
\hline$H 3 b$ & OR $->$ PBC & 0.502 & 8.584 & 0.000 & Supported & & 0.267 & & 0.375 \\
\hline \multicolumn{10}{|c|}{ Factors effecting Entrepreneurial Intention } \\
\hline$H 1$ & ATE -> ENTI & 0.305 & 5.259 & 0.000 & Supported & \multirow{3}{*}{0.456} & 0.103 & \multirow{3}{*}{0.342} & 0.247 \\
\hline$H 2$ & SUN -> ENTI & 0.179 & 3.395 & 0.000 & Supported & & 0.048 & & 0.156 \\
\hline$H 3$ & PBC -> ENTI & 0.337 & 5.232 & 0.000 & Supported & & 0.116 & & 0.361 \\
\hline \multicolumn{10}{|c|}{ Factors effecting Pre-start-up Behaviour } \\
\hline$H 4$ & ENTI -> PRSB & 0.674 & 17.699 & 0.000 & Supported & 0.527 & 0.837 & 0.329 & 0.766 \\
\hline \multicolumn{10}{|c|}{ Moderating effecting Fungibility Issues } \\
\hline H5 & FG $->$ PRSB & -0.017 & 0.376 & 0.353 & Not Supported & & 0.000 & & \\
\hline \multicolumn{10}{|c|}{ Mediating effecting Entrepreneurial Intention } \\
\hline \multirow{3}{*}{ H6 } & ATE $->$ PRSB & 0.206 & 5.051 & 0.000 & Supported & & - & & \\
\hline & SUN -> PRSB & 0.121 & 3.397 & 0.000 & Supported & & - & & \\
\hline & PBC -> PRSB & 0.228 & 4.703 & 0.000 & Supported & & - & & \\
\hline
\end{tabular}

Notes: ATE: Attitude Towards Entrepreneurship; IN: Innovativeness; PP: Proactive Personality; NA: Need for Achievement; IC: Internal Locus of Control; RP: Risk-Taking Propensity; SUN: Subjective Norms; LI: Lifestyle Integration; SN: Social Networking; PBC: Perceived Behavioural Control; RS: Resource; OR: Opportunity Recognition; ENTI: Entrepreneurial Intention; FG: Fungibility Issues; PRSB: Pre-start-up Behaviour.

For the mediating effects of ENTI on ATE, SUN, and PBC with PRSB of Asnaf millennials $\left(\mathrm{H}_{5}\right)$, Table 4 shows the indirect effect coefficients and $p$-value. It is revealed that ATE has a significant positive indirect effect $(p$-value $<0.05)$ on PRSB that verified the mediating effect of ENTI. SUN has statistically significant positive indirect effects $(p$-value $<0.05)$ on the PRSB, which confirmed the mediating effect of ENTI. This study confirmed that $\mathrm{PBC}$ has a significant positive indirect effect ( $p$-value $<0.05$ ) on the PRSB, which verified the mediating effect of ENTI. Lastly, the next hypothesis predicted that FG moderates the relationship between ENTI and PRSB. The findings revealed that EI has no moderating effect on PRSB $\left(\mathrm{H}_{6}\right)$.

\section{Discussion}

This study aimed to identify how the selected factors affect Asnaf millennials' inclination towards entrepreneurship and how their entrepreneurial intention affects pre-start-up behaviour. The first hypothesis $\left(\mathrm{H}_{1 \mathrm{a}}\right)$ tested the effect of $\mathrm{IN}$, which is the degree of a novel idea, original thinking, and creativity on the adopter's current values and needs. There was a positive effect between IN and ATE, which is parallel with the statement that innovativeness affects the attitude towards entrepreneurship [48]. The second hypothesis $\left(\mathrm{H}_{1 \mathrm{~b}}\right)$ determined the effect of PP, which is the level of acting on the environment. It was revealed that PP has significant and positive effects on ATE, which 
parallels the statement that a person with PP would become a leader rather than waiting for other influences, as well as making use of the opportunities and being responsible for any failure that can lead to positive ATE [47]. The third hypothesis $\left(\mathrm{H}_{1 \mathrm{c}}\right)$ examined the effect of NA, which is the tendency to excel and perform at an entrepreneurial job. It was found that NA has a significant positive effect on ATE. The findings revealed that rural Asnaf millennials could set challenging goals, try to excel in tasks, set for job performance regardless of tasks, and maintain high standards in difficult tasks. This finding supports the statement that NA affects ATE [60]. The fourth hypothesis $\left(\mathrm{H}_{1 \mathrm{~d}}\right)$ tested IC, which is personal control, own ability, and efforts as the result of internal influence. There is a significant positive effect between IC and ATE among Asnaf millennials, which parallels the investigation of the effect of IC on ATE [60]. The fifth hypothesis $\left(\mathrm{H}_{1 \mathrm{e}}\right)$ investigated $\mathrm{RP}$, which represents the inclination to undertake risk in becoming an entrepreneur. There is a significant positive effect between RP and ATE among the Asnaf millennials. This finding is the opposite of the previous studies on the effect of RP on ATE $[48,62]$.

The sixth hypothesis $\left(\mathrm{H}_{2 \mathrm{a}}\right)$ tested $\mathrm{LI}$, which is the lifestyle of entrepreneurs that strikes a balance between family and work by getting a decent payment for working on something that they enjoyed. The job has flexible hours and the person could live in a desired location. It was found that LI has a significant positive effect on SUN. The seventh hypothesis $\left(\mathrm{H}_{2 b}\right)$ tested the effect of SN, which has a significant positive effect on SUN. The eighth hypothesis $\left(\mathrm{H}_{3 a}\right)$ examined $\mathrm{RS}$, which is the various source of information on income-generating opportunities. In particular, there is a significant positive effect between RS and PCB. The ninth hypothesis $\left(\mathrm{H}_{3 b}\right)$ tested the availability of OR in the new venture establishment. There is a significant positive effect between OR and PBC.

It was hypothesised that ENTI is positively affected by ATE $\left(\mathrm{H}_{1}\right)$ among the Asnaf millennials, which is parallel with the statement that ENTI is significantly and positively affected by ATE (coefficient of 0.305, $p$-value of 0.000) among the Asnaf millennials. The result is parallel with the statement that ENTI is positively affected by ATE [48]. Moreover, this study predicted that ENTI is positively affected by SUN $\left(\mathrm{H}_{2}\right)$. The results confirmed that ENTI is significantly and positively affected by SUN (coefficient of $0.179, p$-value of 0.000 ). This finding agrees with earlier studies that measured the effects of SUN on ENTI [83]. Lastly, this study predicted that ENTI is positively affected by $\mathrm{PBC}\left(\mathrm{H}_{3}\right)$. The findings supported the claim that ENTI is significantly and positively affected by PBC (coefficient of $0.337, p$-value of 0.000 ). This result is parallel with the statement that ENTI is positively affected by ATE [101].

It was predicted that PRSB is positively affected by ENTI among the Asnaf millennials $\left(\mathrm{H}_{4}\right)$. The results supported the statement that PRSB is significantly and positively affected by EI (coefficient of $0.674, p$-value of $0.000, r^{2}$ value of $0.527, f^{2}$ value of 0.837 , and $Q^{2}$ value of 0.329 ) among the Asnaf millennials. This finding is parallel with the earlier studies on the effects of ENTI on PRSB.

The results confirmed that ENTI fully mediated the relationship between ATE and PRSB $\left(\mathrm{H}_{5}\right)$. The findings further confirmed the full mediation of ENTI on the association of SUN and PRSB of Asnaf millennials $\left(\mathrm{H}_{5}\right)$. The results also confirmed that entrepreneurial intention fully mediated the linkage between PBC and PRSB $\left(\mathrm{H}_{5}\right)$. It is confirmed that the mediation model for this study is convincing and in line with the previous studies [85].

\section{Conclusions}

This study investigated the effect of selected factors on Asnaf millennials' inclination towards entrepreneurship, as well as how their entrepreneurial intention affects their pre-start-up behaviour. All the path coefficients were statistically significant with the excepted outcome variables, such as RP on ATE and the moderating effect of FG on the effect of ENTI on PRSB. It was found that all relationships within the model were positive and there was also a negative pathway. The moderate effect of FG was negative, indicating that when there is less fungible, more effort for pre-start-up will be acquired. 
This study investigated the factors affecting the Asnaf millennials' behaviour on pre-start-up using the decomposed theory of planned behaviour. The results revealed that the decomposed belief of IN, PP, NA, IC, LI, SN, RS, and RS could influence ATE, SUN, and PBC. Moreover, attitude, SUN, and PBC affected ENTI and PRSB. For DTPB, this study contributed by improving the predictive ability using the pre-start-up phase. This study explored how the series of transitions in the pre-start-up become sources of new venture establishment in affecting Asnaf millennials' ENTI and PRSB in deciding the DTPB. This study also validated the DPTB theory in an entrepreneurship setting. For the theoretical implications, this study used DTPB to determine factors influencing new venture establishment. The findings confirmed the significance of DTPB for the new venture of business start-up behaviour. This study contributed by presenting a theory that has been used in several studies $[83,112]$ besides extending the scope in entrepreneurship study with implied expectations on its significance in forecasting the subsequent actions. Four out of five components of personality traits were found to significantly contribute to the attitudinal belief in the present study. This suggests the plausibility of innovativeness, proactiveness, need for achievement, and internal locus of control in determining one's attitude towards entrepreneurship. Besides that, the social factors of lifestyle integration and social networking were also found to be important determinants of subjective norms, while resource and opportunity recognition served as important determinants of perceived behavioural control. Since this study focused on a new venture in the pre-start-up phase, the need to incorporate traits, social factors, resources, and opportunities in other specific categories of the start-up phase in the entrepreneurial process was proposed. To the researcher's knowledge, the present study is deemed as one of the first that has adopted DTPB to determine the establishment of a new venture in Malaysia. In addition, the adoption of DTPB in entrepreneurship settings contributed to the existing body of knowledge on this theory. Moreover, with the local sampling frame and a new venture, the obtained findings of this study were found to support the robustness of the DTPB based on its ability to predict entrepreneurial intention and pre-start-up behaviour. In particular, innovativeness, proactiveness, need for achievement, internal locus of control, lifestyle integration, social networking, resources, and opportunities were found to contribute a direct influence on one's attitude towards entrepreneurship, subjective norms, and perceived behavioural control.

The practical implications of this study provide meaningful insights to academicians and development researchers, professionals, and local and development agencies who are interested in pre-start-up behaviour as a source of new venture establishment. This study also demonstrated multiple paths to promote the involvement of Asnaf millennials in entrepreneurship as a career. Furthermore, the relatively lesser involvement in entrepreneurship provided essential insights and shed light on the potential avenues of developing an action plan to promote entrepreneurship programmes. The findings of this study also offer vast opportunities for local development agencies to increase new venture establishment among those who opt for a business start-up, which will potentially increase the rate of involvement within the Malaysian context. Considering the main concern of millennials in the development of entrepreneurial skills in a new venture, the obtained findings of this present study are expected to benefit Zakat institutions in making entrepreneurship possible. The findings highlighted the importance of pre-venture to the Asnaf millennial community, especially in rural areas that need a small capital venture for an entrepreneurial program. Rural Asnaf millennials might find it difficult to avoid traditional culture when kick-starting their business. Government and non-government development organizations should work towards improving the socio-economic conditions of low-income households in Malaysia by providing access to working capital and enterprise development training programmes. Based on the findings, this study recommends specialized safety-net programmes for vulnerable Asnaf millennials to develop entrepreneurial competencies and specific skills focused on environmentally friendly income-generating activities. It is suggested that the government should develop and empower the existing entrepreneurship programme with detailed goals. More information can be given to the local community as there were 
limited respondents who attended training, only a few established companies, and people have little knowledge of financial facilities.

This study has several limitations and presented recommendations for future research. This study selected respondents who were born between 1980 to 2000, and it was found that the respondents who had not kick started a business were included in the final sample. This study selected 310 respondents for the sample size from Kelantan as the other regions were not included due to geographical distance. The objective measures of ENTI and PRSB are limited due to their specificity. Hence, future research should determine the validity of the investigated models and findings across time. Future research should also enhance the level of specificity and measure all DTPB constructs at various gestation phases, instead of focusing on the aggregate behavioural category. Future research should investigate whether the different intention-action links have different pre-start-up activities, such as producing a creation, leading a market study, constructing a business plan, and following training classes.

Author Contributions: Conceptualization, T.M.A.T.M., A.A.M., G.B.A. and M.D.I.; methodology, T.M.A.T.M. and M.D.I.; software, A.A.M.; validation, A.A.M. and G.B.A.; formal analysis, T.M.A.T.M. and A.A.M.; writing-original draft preparation, T.M.A.T.M. and A.A.M.; writing-review and editing, G.B.A. and M.D.I.; supervision, A.A.M. and M.D.I.; and funding acquisition, M.D.I. and A.A.M.

Funding: This research was funded by the Ministry of Higher Education, Malaysia under the grant entitled "Developing a Comprehensive Rural Entrepreneurship Model for Poverty Eradication (REMODE)" (R/NRGS/A01.00/00047A/006/2014/000149).

Conflicts of Interest: The authors declare no conflict of interest.

\section{Appendix A. Measurement Scale Items}

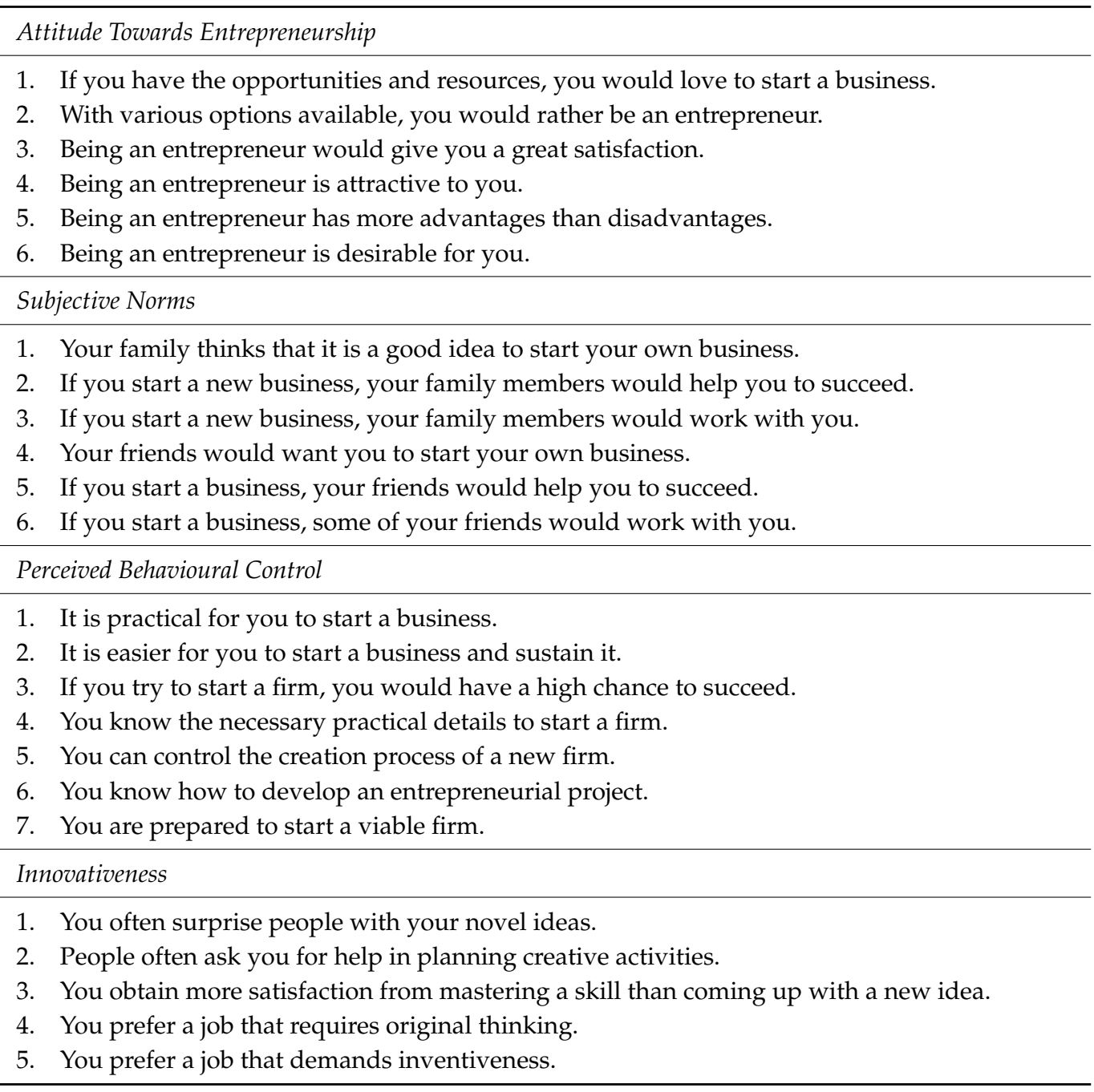


6. You consider yourself as a creative person.

7. You prefer to try different ways of doing a similar thing.

Proactive Personality

1. You are constantly looking for different ways to improve your life.

2. Regardless where you are, you are a powerful force of constructive changes.

3. If you see something you feel not comfortable, you would take action immediately.

4. Despite the challenges you face, if you believe in something, you would make it happen.

5. You are always looking for better ways to do things.

6. If you believe in an idea, you would realise it despite facing obstacles.

Need for Achievement

1. You try to perform your best at work.

2. You enjoy situations that, you can make use of your abilities.

3. It is important for you to do the best job possible.

4. You push yourself to be "all that I can be".

5. You try very hard to improve your work performance.

Internal Locus of Control

1. To a greater extent, your life is controlled by your own.

2. Your life is determined by your own actions.

3. When you get what you want, it is usually because you work hard for it.

4. When you make plans, you are almost certain that you can work them out.

5. The success of your life depends heavily on your ability.

6. You feel you are in control of your life.

Risk Taking Propensity

1. You are ready to take risks.

2. You are willing to take actions that result in unexpected outcomes.

3. You enjoy taking daring actions by doing precarious activities.

4. You treasure chances.

5. You are cautious about unpredictable situations.

6. You accept whatever situations involving personal risk that yield great rewards.

7. You take chances regardless of the risks.

Lifestyle Integration

1. You want to initiate a business in the hope of enjoying a good life.

2. You want to start a business with more activities.

3. You want to start a business to support your financial interests.

4. You want to initiate a business in the hope of meeting interesting people.

5. Serving the community is equally important to financial gain.

Social Networking

1. Contacting people you know helps you get new business opportunities.

2. Asking people you know about possible business ideas.

3. You know a lot of people who might be able to help you start a new business.

4. You can count on relatives, friends, or acquaintances to get information about new business.

5. You know people who might be able to help you search for new business.

6. You use personal connections to promote your own business.

Resource

1. You can successfully acquire important information for starting up a new business.

2. You can acquire managerial knowledge to operate a new business.

3. You can acquire market information for a new business.

4. You can acquire supply chain information for a new business.

5. You can access what consumers want from my business.

6. You can acquire financial resources for my new business. 
Opportunity Recognition

1. You frequently identify opportunities to start up new businesses.

2. If you see a new business opportunity, you would not miss it.

3. You often think about ideas and ways to start a business.

4. In day-to-day activities, you see potential business ideas.

5. You have keen alertness or sensitivity towards new business opportunities.

6. You can see potential new business venture.

Entrepreneurial Intention

1. You are ready to do anything to be an entrepreneur.

2. You will make every effort to start and run your own business.

3. You are determined to create a business in the near future.

4. Your professional goal is to be an entrepreneur.

5. You have put serious thoughts about starting a firm.

6. You have a strong intention to start a business someday.
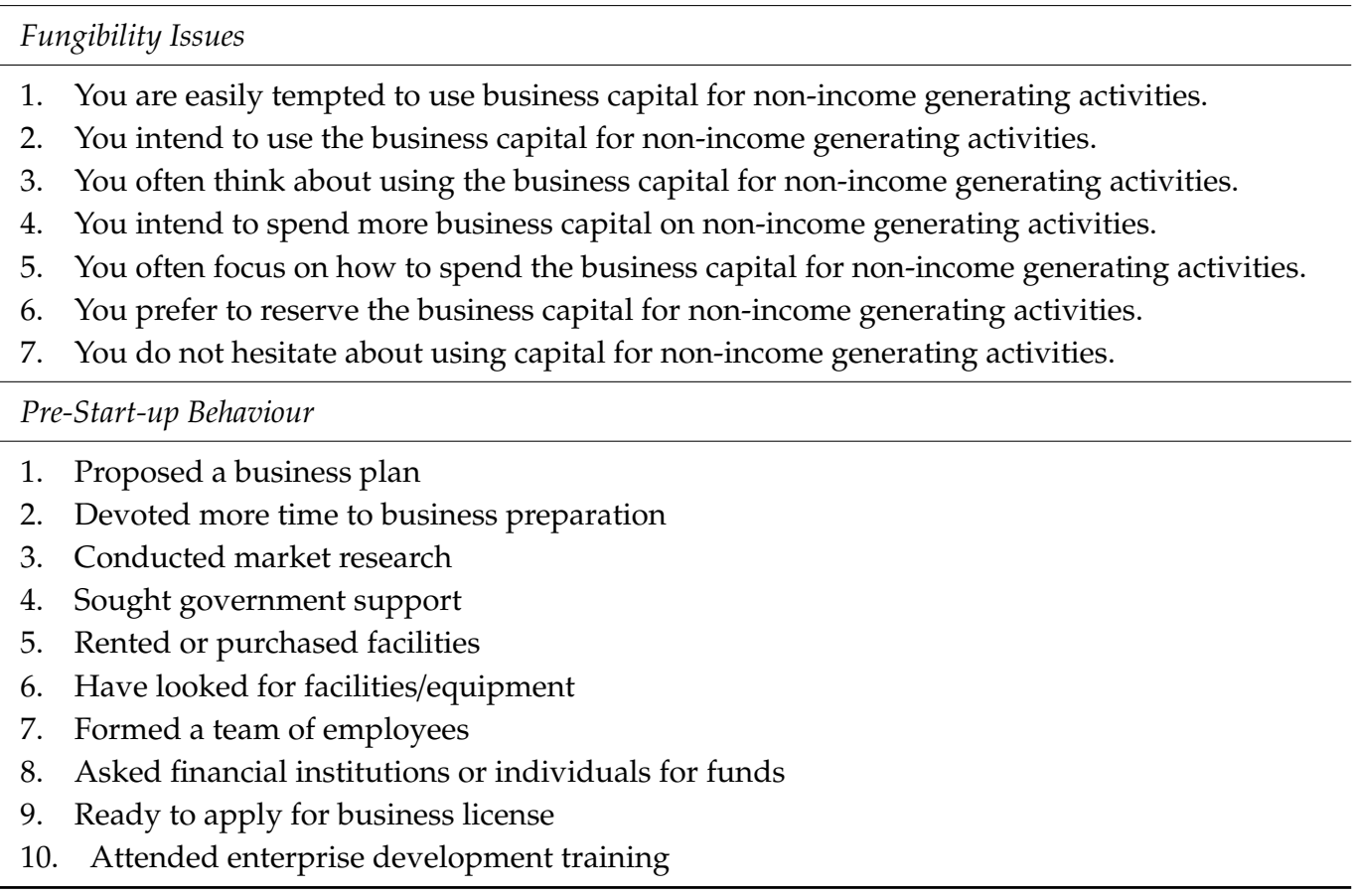

\section{References}

1. Gartner, W.B. A Conceptual Framework for Describing the Phenomenon of New Venture Creation. Acad. Manag. Rev. 1985, 10, 696-706. [CrossRef]

2. Korunka, C.; Frank, H.; Lueger, M.; Mugler, J. The entrepreneurial personality in the context of resources, environment, and the startup process-A configurational approach. Entrep. Theory Pract. 2003, 28, $23-42$. [CrossRef]

3. De Tienne, D.R. Entrepreneurial exit as a critical component of the entrepreneurial process: Theoretical development. J. Bus. Ventur. 2010, 25, 203-215. [CrossRef]

4. Shirokova, G.; Osiyevskyy, O.; Bogatyreva, K. Exploring the intention-behavior link in student entrepreneurship: Moderating effects of individual and environmental characteristics. Eur. Manag. J. 2016, 34, 386-399. [CrossRef]

5. Rahman, R.A.; Ahmad, S. Strategi Pembangunan Keusahawanan Asnaf Fakir dan Miskin melalui Agihan Bantuan Modal Zakat. Jurnal Pengurusan 2011, 33, 37-44.

6. Bahaman, A.S.; Jeffrey, L.S.; Hayrol Azril, M.S.; Jegak, U. Acceptance, attitude and knowledge towards agriculture economic activity between rural and urban youth: The case of contract farming. J. Appl. Sci. 2010, 10, 2310-2315. [CrossRef] 
7. Wasdani, K.P.; Mathew, M. Potential for opportunity recognition along the stages of entrepreneurship. J. Glob. Entrep. Res. 2014, 4, 1-24. [CrossRef]

8. Taylor, S.; Todd, P.A. Understanding Information Technology Usage: A Test of Competing Models. Inf. Syst. Res. 1995, 6, 144-176. [CrossRef]

9. Asimakopoulos, G.; Hernández, V.; Miguel, J.P. Entrepreneurial Intention of Engineering Students: The Role of Social Norms and Entrepreneurial Self-Efficacy. Sustainability 2019, 11, 4314. [CrossRef]

10. Escolar-Llamazares, M.C.; Luis-Rico, I.; Torre-Cruz, T.; Herrero, A.; Jiménez, A.; Palmero-Cámara, C.; Jiménez-Eguizábal, A. The Socio-educational, Psychological and Family-Related Antecedents of Entrepreneurial Intentions among Spanish Youth. Sustainability 2019, 11, 1252. [CrossRef]

11. Wach, K.; Wojciechowski, L. Entrepreneurial Intentions of Students in Poland in the View of Ajzen's Theory of Planned Behaviour. Entrep. Bus. Econ. Rev. 2016, 4, 83-94. [CrossRef]

12. Fang, C.; Chen, L. Exploring the Entrepreneurial Intentions of Science and Engineering Students in China: A Q Methodology Study. Sustainability 2019, 11, 2751. [CrossRef]

13. Voda, A.I.; Florea, N. Impact of Personality Traits and Entrepreneurship Education on Entrepreneurial Intentions of Business and Engineering Students. Sustainability 2019, 11, 1192. [CrossRef]

14. Paunescu, C.; Popescu, M.C.; Duennweber, M. Factors Determining Desirability of Entrepreneurship in Romania. Sustainability 2018, 10, 3893. [CrossRef]

15. Halim, R.R.; Adiwijaya, K.; Haryanto, J. Firmanzah The Propensity of Young Consumers to Overspend on Credit Cards: Decomposition Effect in the Theory of Planned Behavior. J. Econ. Bus. Manag. 2016, 4, 599-605. [CrossRef]

16. Lau, A.S.M. Hospital-based nurses' perceptions of the adoption of Web 2.0 tools for knowledge sharing, learning, social interaction and the production of collective intelligence. J. Med. Internet Res. 2011, 13, 1-12. [CrossRef]

17. Moons, I.; De Pelsmacker, P. An extended decomposed theory of planned behaviour to predict the usage intention of the electric car: A multi-group comparison. Sustainability 2015, 7, 6212-6245. [CrossRef]

18. Tao, C.C.; Fan, C.C. A modified decomposed theory of planned behaviour model to analyze user intention towards distance-based electronic toll collection services. Promet-Traffic Transp. 2017, 29, 85-97. [CrossRef]

19. Cheng, M.J.; Hung, S.W.; Tsai, H.H.; Chen, P.W. The Adoption Intentions of Mobile Applications. In Proceedings of the 15th International Conference on Computer and Information Science, Okayama, Japan, 26-29 June 2016. [CrossRef]

20. Gangwal, N.; Bansal, V. Application of Decomposed Theory of Planned Behavior for M-commerce Adoption in India. In Proceedings of the 18th International Conference on Enterprise Information Systems, Rome, Italy, 25-28 April 2016; Available online: https://pdfs.semanticscholar.org/9120/ 2196cfcdb8c4e1a429f0000cd615da2c784c.pdf (accessed on 4 August 2019).

21. Zhang, L.; Fan, Y.; Zhang, W.; Zhang, S. Extending the Theory of Planned Behavior to Explain the effects of Cognitive Factors across Different Kinds of Green Products. Sustainability 2019, 11, 4222. [CrossRef]

22. Tu, J.-C.; Yang, C. Key Factors Influencing Consumers' Purchase of Electric Vehicles. Sustainability 2019, 11, 3863. [CrossRef]

23. Al Mamun, A.; Masud, M.M.; Fazal, S.A.; Muniady, R. Green vehicles adoption behaviour among low-income households: Evidence from coastal Malaysia. Environ. Sci. Pollut. Res. 2019. [CrossRef] [PubMed]

24. Yi, S. Determinants of Consumers' Purchasing Behavior for Certified Aquaculture Products in South Korea. Sustainability 2019, 11, 3840. [CrossRef]

25. Al Mamun, A.; Mohamad, M.R.; Yaacob, M.R.; Mohiuddin, M. Intention and Behavior towards Green Consumption among Low-Income Households. J. Environ. Manag. 2018, 227, 73-86. [CrossRef] [PubMed]

26. Ahmad, A.R.; Wan Yusoff, W.F.; Md Noor, H.; Ramin, A.K. Peliminary Study of Rural Entrepreneurship Development Program in Malaysia. J. Glob. Entrep. 2012, 2, 1-8.

27. Howes, N.; Strauss, W. Managing for The Long Term: Big Picture: The Next 20 years. Harv. Bus. Rev. 2007, May-June, 41-52.

28. Thompson, E.R. Entrepreneurial Intent: And Development Reliable Metric. Entrep. Theory Pract. 2009, 33, 669-695. [CrossRef]

29. Yusof, M.; Sandhu, M.S.; Jain, K.K. Relationship between psychological characteristics and entrepreneurial inclination: A case study of students at University Tun Abdul Razak. J. Asia Entrep. Sustain. 2007, 3, $23-41$. 
30. Gagnier, C.M. Millennial-Generated Change to American Governance. Natl. Civ. Rev. 2008, 97, 32-36. [CrossRef]

31. Koe, W.L.; Majid, I.A. Socio-Cultural Factors and Intention towards Sustainable Entrepreneurship. Eurasian J. Bus. Econ. 2014, 7, 145-156.

32. Barton, M.; Schaefer, R.; Canavati, S. To Be or Not to Be a Social Entrepreneur: Motivational Drivers amongst American Business Students. Entrep. Bus. Econ. Rev. 2018, 6, 9-35. [CrossRef]

33. Salamzadeh, A.; Kirby, D.A. New venture creation: How start-ups grow? Administer 2017, 30, 9-29. [CrossRef]

34. Atherton, A. Preparing for business start-up: "pre-start" activities in the new venture creation dynamic. J. Small Bus. Enterp. Dev. 2007, 14, 404-417. [CrossRef]

35. Reynolds, P.; Storey, D.J.; Westhead, P. Cross-national comparisons of the variation in new firm formation rates. Reg. Stud. 1994, 28, 443-456. [CrossRef]

36. Aldrich, H.E.; Martinez, M.A. Many are called, but few are chosen: An evolutionary perspective for the study of entrepreneurship. Entrep. Theory Pract. 2001, 25, 41-56. [CrossRef]

37. LeBrasseur, R.; Zanibbi, L.; Zinger, T.J. Growth momentum in the early stages of small business start-ups. Int. Small Bus. J. 2003, 21, 315-330. [CrossRef]

38. Farmer, S.M.; Yao, X.; Kung-Mcintyre, K. The behavioral impact of entrepreneur identity aspiration and prior entrepreneurial experience. Entrep. Theory Pract. 2011, 35, 245-273. [CrossRef]

39. Van Auken, H.E.; Neeley, L. Pre-launch preparations and the acquisition of start-up capital by small firms. J. Dev. Entrep. 2000, 5, 169-178.

40. Van Gelderen, M.; Thurik, R.; Bosma, N. Success and risk factors in the pre-startup phase. Small Bus. Econ. 2006, 26, 319-335. [CrossRef]

41. Alsos, G.A.; Kolvereid, L. The business gestation process of novice, serial, and parallel business founders. Entrep. Theory Pract. 1998, 22, 101-114. [CrossRef]

42. Ajzen, I.; Madden, T.J. Prediction of goal-directed behavior: Attitudes, intentions, and perceived behavioral control. J. Exp. Soc. Psychol. 1986, 22, 453-474. [CrossRef]

43. Fini, R.; Grimaldi, R.; Marzocchi, G.L.; Sobrero, M. The determinants of corporate entrepreneurial intention within small and newly established firms. Entrep. Theory Pract. 2012, 36, 387-414. [CrossRef]

44. Naia, A.; Baptista, R.; Biscaia, R.; Januário, C.; Trigo, V. Entrepreneurial intentions of Sport Sciences students And Theory of Planned Behavior. Motriz Rev. Educ. Fís. 2017, 23, 14-21. [CrossRef]

45. Mwatsika, C. Entrepreneurship development and entrepreneurial orientation in rural areas in Malawi. Afr. J. Bus. Manag. 2015, 9, 425-436.

46. Van Gelderen, M.; Brand, M.; van Praag, M.; Bodewes, W.; Poutsma, E.; Van Gils, A. Explaining entrepreneurial intentions by means of the theory of planned behaviour. Career Dev. Int. 2008, 13, 538-559. [CrossRef]

47. Gird, A.; Bagraim, J.J. The theory of planned behaviour as predictor of entrepreneurial intent amongst final-year university students. S. Afr. J. Psychol. 2008, 38, 711-724. [CrossRef]

48. Douglas, E.J.; Shepherd, D.A. Self-employment as a career choice: Attitudes, entrepreneurial intentions, and utility maximization. Entrep. Theory Pract. 2002, 26, 81-90. [CrossRef]

49. McCrae, R.R.; Costa, P.T., Jr. A five-factor theory of personality. In Handbook of Personality: Theory and Research; Pervin, L., John, O.P., Eds.; Guilford Press: New York, NY, USA, 1999; pp. 139-153.

50. Otuedon, M.U. Emotions, personality, emotional intelligence and leadership in the workplace: The prevailing attitude. Int. J. Econ. Commer. Manag. 2016, 4, 350-368.

51. Gurol, Y.; Atsan, N. Entrepreneurial characteristics amongst university students: Some insights for entrepreneurship education and training in Turkey. Educ. Train. 2006, 48, 25-38. [CrossRef]

52. Rokhman, W.; Ahamed, F. The Role of Social and Psychological Factors on Entrepreneurial Intention among Islamic College Students in Indonesia. Entrep. Bus. Econ. Rev. 2015, 3, 29-42. [CrossRef]

53. Rauch, A.; Frese, M. Let's put the person back into entrepreneurship research: A meta-analysis on the relationship between business owners' personality traits, business creation, and success. Eur. J. Work Organ. Psychol. 2007, 16, 353-385. [CrossRef]

54. Gupta, V.; MacMillan, I.C.; Surie, G. Entrepreneurial leadership: Developing and measuring a cross-cultural construct. J. Bus. Ventur. 2004, 19, 241-260. [CrossRef]

55. Okudan, G.E.; Rzasa, S.E. A project-based approach to entrepreneurial leadership education. Technovation 2006, 26, 195-210. [CrossRef] 
56. Chen, M.H. Entrepreneurial leadership and new ventures: Creativity in entrepreneurial teams. Creat. Innov. Manag. 2007, 16, 239-249. [CrossRef]

57. Wang, Y.L.; Ellinger, A.D.; Jim Wu, Y.C. Entrepreneurial opportunity recognition: An empirical study of R\&D personnel. Manag. Decis. 2013, 51, 248-266.

58. Armstrong, S.J.; Hird, A. Cognitive style and entrepreneurial drive of new and mature business owner-managers. J. Bus. Psychol. 2009, 24, 419-430. [CrossRef]

59. Rexhepi, G.; Kurtishi, S.; Bexheti, G. Corporate social responsibility (CSR) and innovation-the drivers of business growth? Procedia-Soc. Behav. Sci. 2013, 75, 532-541. [CrossRef]

60. Bateman, T.S.; Crant, J.M. The proactive component of organizational behavior: A measure and correlates. J. Organ. Behav. 1993, 14, 103-118. [CrossRef]

61. Kuratko, D.F. Entrepreneurial leadership in the 21st century: Guest editor's perspective. J. Leadersh. Organ. Stud. 2007, 13, 1-11. [CrossRef]

62. Surie, G.; Ashley, A. Integrating pragmatism and ethics in entrepreneurial leadership for sustainable value creation. J. Bus. Ethics 2008, 81, 235-246. [CrossRef]

63. Aaijaz, N.; Ibrahim, M.D. Are Women Students More Inclined Towards Entrepreneurship. J. Bus. Rev. 2013, 2, 1-14.

64. Zhao, H.; Seibert, S.E. The Big Five personality dimensions and entrepreneurial status: A meta-analytical review. J. Appl. Psychol. 2006, 91, 259-271. [CrossRef] [PubMed]

65. Okhomina, D. Entrepreneurial orientation and psychological traits: The moderating influence of supportive environment. J. Behav. Stud. Bus. 2010, 2, 1-16.

66. Jackson, D.N. Personality Research Form Manual; Research Psychologists Press: Goshen, NY, USA, 1974.

67. Rotter, J.B. Generalized expectancies for internal versus external control of reinforcement. Psychol. Monogr. Gen. Appl. 1966, 80, 1-28. [CrossRef]

68. Diaz, F.; Rodriguez, A. Locus of control and values of community entrepreneurs. Soc. Behav. Personal. 2003, 31, 739-748. [CrossRef]

69. Yan, J. The impact of entrepreneurial personality traits on perception of new venture opportunity. N. Engl. J. Entrep. 2010, 13, 21-35. [CrossRef]

70. Robinson, P.B.; Stimpson, D.V.; Huefner, J.C.; Hunt, H.K. An attitude approach to the prediction of entrepreneurship. Entrep. Theory Pract. 1991, 15, 13-30. [CrossRef]

71. Ozaralli, N.; Rivenburgh, N.K. Entrepreneurial intention: Antecedents to entrepreneurial behavior in the USA and Turkey. J. Glob. Entrep. Res. 2016, 6, 3. [CrossRef]

72. Karimi, S.; Biemans, H.J.; Naderi, K.; Lans, T.; Chizari, M.; Mulder, M. Testing the relationship between personality characteristics, contextual factors and entrepreneurial intentions in a developing country. Int. J. Psychol. 2017, 52, 227-240. [CrossRef] [PubMed]

73. Ajzen, I. The theory of planned behavior. Organ. Behav. Hum. Decis. Process. 1991, 50, 179-211. [CrossRef]

74. Ajzen, I. From intentions to actions: A theory of planned behavior. In Action Control; Springer: Berlin/Heidelberg, Germany, 1985; pp. 11-39.

75. Yordanova, D.I.; Tarrazon, M.A. Gender differences in entrepreneurial intentions: Evidence from Bulgaria. J. Dev. Entrep. 2010, 15, 245-261. [CrossRef]

76. Claire, L. Re-Storying the Entrepreneurial Ideal: Lifestyle Entrepreneurs as Hero? Tamara J. Crit. Organ. Inq. 2012, 10, 31-39.

77. Sequeira, J.; Mueller, S.L.; McGee, J.E. The influence of social ties and self-efficacy in forming entrepreneurial intentions and motivating nascent behavior. J. Dev. Entrep. 2007, 12, 275-293. [CrossRef]

78. Ulhoi, J.P. The social dimensions of entrepreneurship. Technovation 2005, 25, 939-946. [CrossRef]

79. Yzer, M. Perceived behavioral control in reasoned action theory: A dual-aspect interpretation. Ann. Am. Acad. Political Soc. Sci. 2012, 640, 101-117. [CrossRef]

80. Samuel, Y.A.; Ernest, K.; Awuah, J.B. An assessment of entrepreneurship intention among Sunyani Polytechnic Marketing Students. Int. Rev. Manag. Mark. 2013, 3, 37-49.

81. Quan, X.; Motoyama, Y. Empirical disaggregation of social networks: A study of ethnic professional associations and entrepreneurship in Silicon Valley. J. Small Bus. Entrep. 2010, 23, 509-526. [CrossRef]

82. Krishnamoorthy, V.; Balasubramani, R. Motivational factors among women entrepreneurs and their entrepreneurial success: A study. Int. J. Manag. Res. Bus. Strategy 2014, 3, 13-26. 
83. Ngorora, G.P.K.; Mago, S. Challenges of rural entrepreneurship in South Africa: Insights from nkonkobe municipal area in the Eastern Cape Province. Int. J. Inf. Technol. Bus. Manag. 2013, 16, 1-11.

84. Wu, L.Y. Entrepreneurial resources, dynamic capabilities and start-up performance of Taiwan's high-tech firms. J. Bus. Res. 2007, 60, 549-555. [CrossRef]

85. Krueger, N., Jr.; Dickson, P.R. How believing in ourselves increases risk taking: Perceived self-efficacy and opportunity recognition. Decis. Sci. 1994, 25, 385-400. [CrossRef]

86. Krueger, N.F., Jr. What lies beneath? The experiential essence of entrepreneurial thinking. Entrep. Theory Pract. 2007, 31, 123-138. [CrossRef]

87. Hunter, M. A typology of entrepreneurial opportunity. Econ. Manag. Financ. Mark. 2013, 8, 128.

88. Dohse, D.; Walter, S.G. Knowledge context and entrepreneurial intentions among students. Small Bus. Econ. 2012, 39, 877-895. [CrossRef]

89. Gartner, W.B. 'Who is an entrepreneur?' is the wrong question. Entrep. Theory Pract. 1989, 13, 47-68. [CrossRef]

90. Lee, S.H.; Wong, P.K. An exploratory study of technopreneurial intentions: A career anchor perspective. J. Bus. Ventur. 2004, 19, 7-28. [CrossRef]

91. Kautonen, T.; van Gelderen, M.; Fink, M. Robustness of the theory of planned behavior in predicting entrepreneurial intentions and actions. Entrep. Theory Pract. 2015, 39, 655-674. [CrossRef]

92. Baharun, R.; Mirghasemi, F.; Rahman, N.S.A.; Awang, Z. Application of Decomposed Theory of Planned Behavior on Post Graduate Students Toward On-Line Shopping. Jurnal Kemanusiaan 2015, 13, 30-42.

93. Shefrin, H.M.; Thaler, R.H. The Behavioral Life-Cycle Hypothesis. Econ. Inq. 1998, 26, 609-643. [CrossRef]

94. Cohen, L.; Manion, L. Research Methods in Education, 4th ed.; Routledge: London, UK, 1994.

95. Ali, A.M.F.; Rashid, Z.A.; Johari, F.; Aziz, M.R.A. The Effectiveness of Zakat in Reducing Poverty Incident: An Analysis in Kelantan, Malaysia. Asian Soc. Sci. 2015, 11, 355-367.

96. Abdullah, I.H.T.; Yusoff, N.A.; Rahman, R.A. Quality of Life and Income Level of Kelantan State Poverty in Malaysia. J. Appl. Environ. Biol. Sci. 2016, 6, 51-57.

97. Carter, N.M.; Gartner, W.B.; Reynolds, P.D. Exploring start-up event sequences. J. Bus. Ventur. 1996, 11, 151-166. [CrossRef]

98. Linan, F. Skill and value perceptions: How do they affect entrepreneurial intentions? Int. Entrep. Manag. J. 2008, 4, 257-272. [CrossRef]

99. Baughn, C.; Cao, J.S.R.; Thi, L.; Le, M.Y.; Lim, V.A.; Neupert, K.E. Normative, social and cognitive predictors of entrepreneurial interest in china, vietnam and the Philippines. J. Dev. Entrep. 2006, 11, 57-77. [CrossRef]

100. Linan, F.; Chen, Y.W. Development and Cross-Cultural application of a specific instrument to measure entrepreneurial intentions. Entrep. Theory Pract. 2009, 33, 593-617. [CrossRef]

101. McClelland, D.C. N achievement and entrepreneurship: A longitudinal study. J. Personal. Soc. Psychol. 1965, 1, 389. [CrossRef] [PubMed]

102. Lang, J.W.B.; Fries, S. A revised 10-item version of the Achievement Motives Scale: Psychometric properties in German-speaking samples. Eur. J. Psychol. Assess. 2006, 22, 216-224. [CrossRef]

103. Getz, D.; Petersen, T. Growth and profit-oriented entrepreneurship among family business owners in the tourism and hospitality industry. Int. J. Hosp. Manag. 2005, 24, 219-242. [CrossRef]

104. Li, Y.; Miao, L.; Zhao, X.; Lehto, X. When family rooms become guest lounges: Work-family balance of B\&B innkeepers. Int. J. Hosp. Manag. 2013, 34, 138-149.

105. Crawford, A.; Jill, N. Exit Planning of Lifestyle and Profit-Oriented Entrepreneurs in Bed and Breakfasts. Int. J. Hosp. Tour. Adm. 2016, 17, 260-285. [CrossRef]

106. Hoye, G.; Hooft, E.A.; Lievens, F. Networking as a job search behaviour: A social network perspective. J. Occup. Organ. Psychol. 2009, 82, 661-682. [CrossRef]

107. Baron, R.A.; Tang, J. Entrepreneurs' social skills and new venture performance: Mediating mechanisms and cultural generality. J. Manag. 2009, 35, 282-306. [CrossRef]

108. Ozgen, E.; Baron, R.A. Social sources of information in opportunity recognition: Effects of mentors, industry networks, and professional forums. J. Bus. Ventur. 2007, 22, 174-192. [CrossRef]

109. Stromback, C.; Lind, T.; Skagerlund, K.; Vastfjall, D.; Tinghog, G. Does self-control predict financial behavior and financial well-being? J. Behav. Exp. Financ. 2017, 14, 30-38. [CrossRef]

110. Kautonen, T.; Van Gelderen, M.; Tornikoski, E.T. Predicting entrepreneurial behaviour: A test of the theory of planned behaviour. Appl. Econ. 2013, 45, 697-707. [CrossRef] 
111. Reio, T.G. The Threat of Common Method Variance Bias to Theory Building. Hum. Resour. Dev. Rev. 2010, 9 , 405-411. [CrossRef]

112. Podsakoff, P.M.; MacKenzie, S.B.; Lee, J.Y.; Podsakoff, N.P. Common method biases in behavioral research: A critical review of the literature and recommended remedies. J. Appl. Psychol. 2003, 88, 879-903. [CrossRef]

113. Hair, J.F.; Black, W.C.; Babin, B.J.; Anderson, R.E.; Tatham, R.L. Multivariate Data Analysis, 6th ed.; Pearson: Upper Saddle River, NJ, USA, 2006.

114. Werts, C.E.; Linn, R.L.; Jöreskog, K.G. Intraclass reliability estimates: Testing structural assumptions. Educ. Psychol. Meas. 1974, 34, 25-33. [CrossRef]

115. Chin, W.W. The Partial Least Squares Approach to Structural Equation Modelling. Mod. Methods Bus. Res. 1998, 295, 295-336.

116. Fornell, C.; Larcker, D.F. Structural equation models with unobservable variables and measurement error: Algebra and statistics. J. Mark. Res. 1981, 18, 382-388. [CrossRef]

117. Edelman, L.F.; Brush, C.G.; Manolova, T. Co-alignment in the resource-performance relationship: Strategy as mediator. J. Bus. Ventur. 2005, 20, 359-383. [CrossRef]

(C) 2019 by the authors. Licensee MDPI, Basel, Switzerland. This article is an open access article distributed under the terms and conditions of the Creative Commons Attribution (CC BY) license (http://creativecommons.org/licenses/by/4.0/). 